\title{
Influence of Soil Parameters on Detecting Voids behind a Tunnel Lining Using an Impact Echo Method
}

\author{
Meng Ma ${ }^{1,2, * \mathbb{C}}$, Rongning Cao ${ }^{1,2} \mathbb{D}$, Chao $\mathrm{Niu}^{3}$, Hougui Zhang ${ }^{4}$ and Weining Liu ${ }^{1,2}$ \\ 1 Key Laboratory of Urban Underground Engineering of Ministry of Education, Beijing Jiaotong University, \\ Beijing 100044, China; 15115267@bjtu.edu.cn (R.C.); wnliu@bjtu.edu.cn (W.L.) \\ 2 School of Civil Engineering, Beijing Jiaotong University, Beijing 100044, China \\ 3 CCCC Highway Consultants Co. Ltd., Beijing 100088, China; xing06he07@163.com \\ 4 Beijing Municipal Institute of Labour Protection, Beijing 100054, China; hugo.zhg@icloud.com \\ * Correspondence: mameng_02231250@163.com
}

Received: 24 November 2019; Accepted: 8 December 2019; Published: 10 December 2019

\begin{abstract}
Tunnel lining cavities are a common problem that may affect the bearing capacity of the tunnel-supporting structure, as well as the tunnel service life. The impact echo (IE) method can be used to detect voids behind tunnel linings. For a long tunnel, the surrounding rocks/soils are inhomogeneous and anisotropic, with parameters that vary with tunnel mileages. It is interesting to analyse whether alterations of the soil parameters affect the non-destructive test results. A laboratory experiment was performed in this study, in which voids behind a concrete plate, representing the tunnel lining, were designed to model the ineffective contact between the soil and the tunnel. The IE method was employed to inspect the existence of the void using different signal analysis approaches in the time, frequency and time-frequency domains. Furthermore, the fractal box-counting dimension was calculated for the purpose of quantitative evaluation. Different soil parameters and void sizes were considered, and finally, a finite element model was built and parameter analysis was accomplished using the software ABAQUS. The results demonstrated that: (1) A comprehensive analysis of vibration signals in the time, frequency and time-frequency domains was useful for identifying voids, while the box-counting dimension was useful for evaluating voids quantitatively. (2) Soils with large density and Young's modulus differences had a certain influence on void detection, while those with large water content and Poisson's ratio differences had little influence. (3) The box-counting dimension value was stable within the area where the void existed behind the tunnel; when the detection point was beyond twice that of the void dimension, it was difficult to locate the void.
\end{abstract}

Keywords: non-destructive test; impact echo method; tunnel void detection; laboratory test; fractal analysis

\section{Introduction}

With the development and large-scale construction of high-speed railways and urban mass transit in China in recent years, different types of lining quality defects have appeared as a result of various adverse factors, such as geological and topographical conditions, natural disasters and related problems during design, construction and operation management. The ineffective bonding state between the lining and ground is a significant factor that can directly induce numerous tunnel issues and affect the tunnel structure safety [1]. Accordingly, it is essential to evaluate the void conditions behind the tunnel lining. Existing detection methods include core drilling, geological radar, the impact echo (IE) method and other non-destructive test (NDT) approaches.

The IE method has been used for pile and other plate-like concrete NDTs [2,3]. During a tunnel NDT, excitation was conducted using an impact hammer on the tunnel lining surface and reflection 
was acquired using a vibration sensor. Due to the existence of structural defects, the tested signals differ. Therefore, one of the key techniques is recognising the existence and location of defects by means of different signal analysis approaches; for example, in the time domain [2,4] or frequency domain $[5,6]$, by using dynamic stiffness or mobility $[7,8]$ and with comprehensive time-frequency approaches $[9,10]$.

Olson et al. [11] evaluated the conditions of concrete-lined tunnels and shafts by means of IEs, impulse response and spectral analysis of surface waves. Guevremont et al. [12] presented tests performed using IEs for shotcrete thickness measurement. The NDT thickness measurements exhibited a strong agreement with the results obtained by mine personnel using conventional methods. Bosela et al. [13] compared four NDT techniques to detect delaminations/flaws in a reinforced concrete tunnel liner, and the results showed that the IE method provided maximum flaw detection. Aggelis et al. [14] combined the use of time domain characteristics, spectral content and wavelet transforms to reveal the effectiveness of grouting by using IEs, and their study indicated that the IE method was valuable for a quick and reliable grouting assessment. Lehmann [15] inspected a section of a power tunnel concrete liner in Nepal using IEs and cores were drawn from selected locations for calibration purposes. Song and Cho [16-18] investigated IEs for evaluating tunnel shotcrete by using both an experimental study and a numerical simulation. Boone et al. [19] tested a three-layer model concrete tunnel lining using a combined stress wave propagation method. The results indicated that a combination of the spectral analysis of surface waves and IE methods provided a more efficient procedure. Gibson [20] summarised research progress on evaluating tunnel shotcrete using IEs. The waveform attenuation characteristic was suggested for evaluating the contact condition between the tunnel lining and surrounding rocks, and the P-wave velocity was proposed as a method for evaluating the early strength of shotcrete. Ryden et al. [21] proposed a method based on the IE amplification factor (Q-factor) for the quality control of backfill material in segmental-lined tunnels. The results indicate that the measured IE Q-factor can be directly related to the backfill material quality. Azari et al. [22] tested the Chesapeake Channel Tunnel in Virginia using ultrasonic surface waves (USW) and IEs. The results indicated that in intact areas, the IE method could provide the thickness of the concrete lining and roadway wall, while in defective areas, the IE method exhibited frequency peaks that differed from the expected thickness frequency. Cao et al. [23] used IEs to detect the voids behind the tunnel lining using different signal analysis approaches.

The research studies mentioned above demonstrate that the IE method is a useful NDT method. Nevertheless, compared to the inspection of piles or plates, it is far more difficult to apply to tunnel inspection as a result of the complicated soil-structure interaction, as well as the wave propagation and reflection, in a 3D structure. For a long tunnel, the soils behind the tunnel are inhomogeneous and anisotropic. The characteristics and parameters (such as mass density, wave velocity and damping) of the surrounding rocks/soils vary at different tunnel mileages. However, few existing studies have analysed whether alteration of soil parameters affects the NDT results. In this study, a principal experiment was designed and performed in the laboratory. The voids behind the concrete plate, modelling the tunnel lining, were designed to model the ineffective contact between the soil and tunnel. The IE method was employed to inspect the existence of voids by means of different signal analysis approaches. Then, by changing the soil parameters, the influence of soil parameters on detecting voids behind the tunnel lining was analysed. Finally, a finite element (FE) numerical simulation of the IE process and parameter analysis were accomplished using the software ABAQUS (Abaqus/cae 6.14.4, Dassault Systemes, Welize-villacubrai, France). 


\section{Experimental Outline}

\subsection{Experimental Design}

When inspecting the voids behind tunnel linings using the IE method, a vibration signal was excited using a hand hammer, and the reflection wave responses from internal flaws, material layers or other interfaces were recorded (Figure 1).

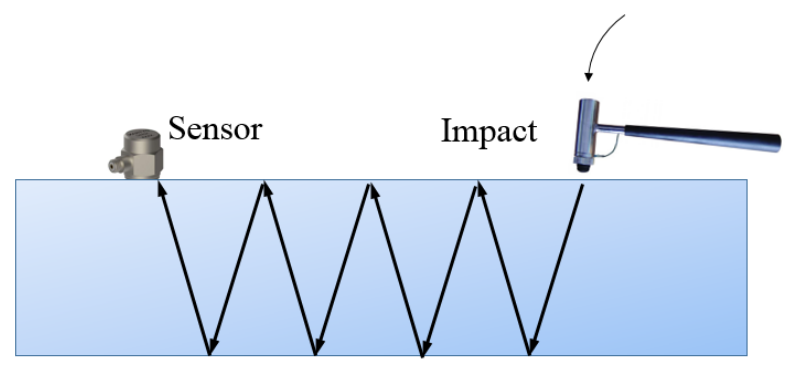

Figure 1. Sketch of measurement principal using the impact echo (IE) method.

Figure 2 provides sketches describes how voids behind the tunnel lining and the concrete plate are detected with the IE method, and similar principles can be found in the different cases. Therefore, the second case (Figure 2b) was employed to model the ineffective contact between the soil and the tunnel.

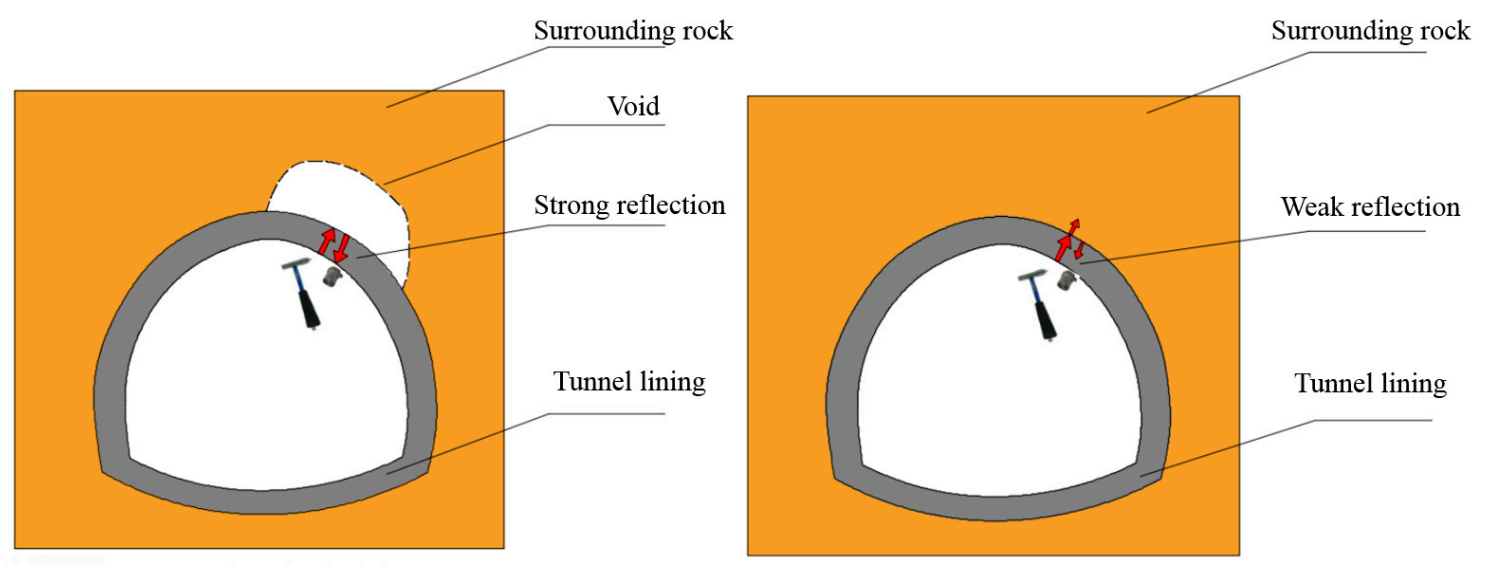

(a)
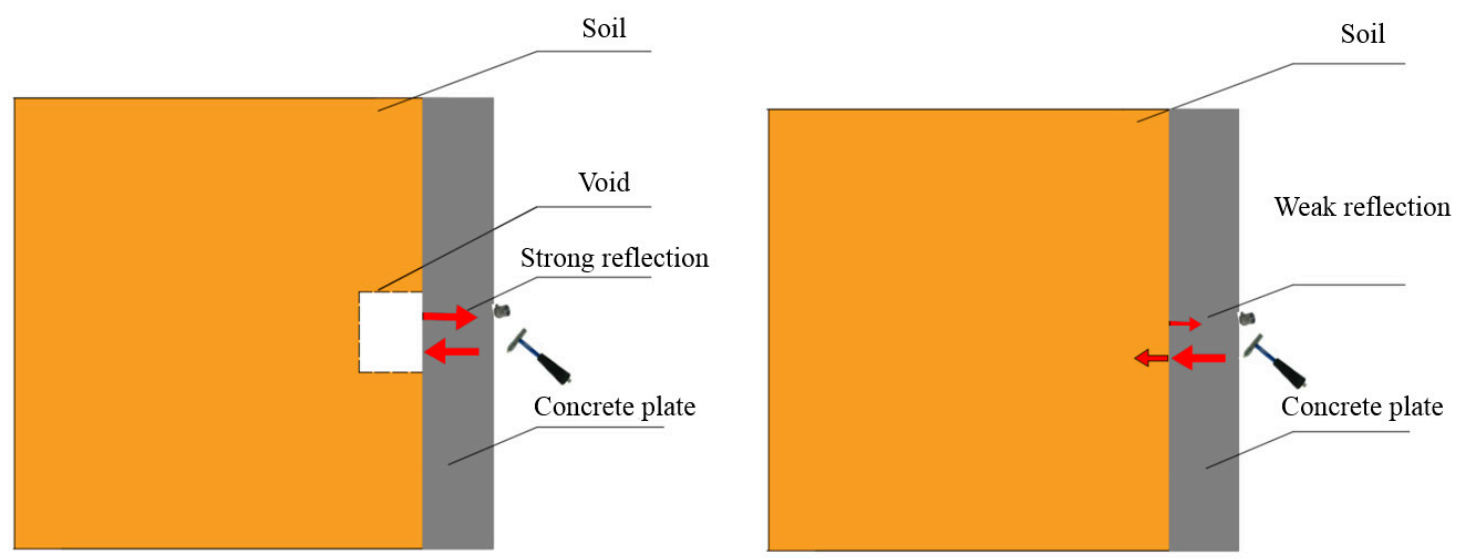

(b)

Figure 2. Sketch describing the detection of voids behind (a) the tunnel lining and (b) the concrete plate using the IE method. 
It should be noted that the laboratory experiment was a principal test rather than a model one. Regulation of the NDT result contributed by the soil parameters was given more attention than the tested values. Furthermore, the similarity coefficient was not considered in the principal test. An empty box was pre-embedded to model the poor contact between the soil and concrete plate.

\subsection{Test Cases}

Three test groups were designed, which considered the alteration of soil parameters and void dimensions. All test cases are listed in Table 1.

Table 1. Test cases.

\begin{tabular}{|c|c|c|c|c|c|}
\hline \multirow{2}{*}{$\begin{array}{c}\text { Case } \\
\text { Description }\end{array}$} & \multicolumn{2}{|c|}{ Case Number } & \multirow{2}{*}{$\begin{array}{l}\text { Mass Density } \\
\left(\mathrm{kg} / \mathrm{m}^{3}\right)\end{array}$} & \multirow{2}{*}{$\begin{array}{c}\text { Water Content } \\
(\%)\end{array}$} & \multirow{2}{*}{$\begin{array}{l}\text { Void Dimension } \\
(\mathrm{mm} \times \mathbf{m m} \times \mathbf{m m})\end{array}$} \\
\hline & Without Void & With Void & & & \\
\hline \multirow{3}{*}{$\begin{array}{l}\text { Density } \\
\text { alteration }\end{array}$} & D1 & - & $\rho_{1}=1578$ & \multirow{3}{*}{$\omega_{1}$} & - \\
\hline & D2 & - & $\rho_{2}=1629$ & & - \\
\hline & D3 & D3v & $\rho_{3}=1656$ & & $V_{1}$ \\
\hline \multirow{3}{*}{$\begin{array}{l}\text { Water content } \\
\text { alteration }\end{array}$} & W1 & W1v & \multirow{3}{*}{$\rho_{3}$} & $\omega_{1}=0.3$ & $V_{1}$ \\
\hline & W2 & $\mathrm{W} 2 \mathrm{v}$ & & $\omega_{2}=8.2$ & $V_{1}$ \\
\hline & W3 & W3v & & $\omega_{3}=15.3$ & $V_{1}$ \\
\hline \multirow{3}{*}{$\begin{array}{l}\text { Void dimension } \\
\text { alteration }\end{array}$} & - & $\mathrm{V} 1$ & \multirow{3}{*}{$\rho_{3}$} & \multirow{3}{*}{$\omega_{1}$} & $V_{1}=150 \times 150 \times 100$ \\
\hline & - & $\mathrm{V} 2$ & & & $V_{2}=100 \times 100 \times 100$ \\
\hline & - & V3 & & & $V_{3}=50 \times 50 \times 100$ \\
\hline
\end{tabular}

First, the soil mass density was considered. In this test group, the water content was set to the natural water content $\omega_{1}=0.3 \%$. In case D1, the density was $\rho_{1}=1578 \mathrm{~kg} / \mathrm{m}^{3}$ when the soil was naturally accumulated. Then, the soil was rammed until the density was $\rho_{2}=1629 \mathrm{~kg} / \mathrm{m}^{3}$, and again until the density reached $\rho_{3}=1656 \mathrm{~kg} / \mathrm{m}^{3}$. The density was calculated by weighing the mass and measuring the filled soil volume. A void condition D3v was designed only for the highest density case, as embedding an empty box between the soil and concrete plate would disturb the soil if its density was low. Using this test group, the influence of mass density on the concrete plate responses was studied.

Next, the water content was considered. In this test group, the dry density was set to $\rho_{3}$. Three different water contents were tested: $\omega_{1}=0.3 \%, \omega_{2}=8.2 \%$ and $\omega_{3}=15.3 \%$. For each case in this test group, comparisons with void conditions $\mathrm{W} 1 \mathrm{v}, \mathrm{W} 2 \mathrm{v}$ and $\mathrm{W} 3 \mathrm{v}$ were designed. The box dimensions remained as $V_{1}=150 \mathrm{~mm} \times 150 \mathrm{~mm} \times 100 \mathrm{~mm}$. Using this test group, the influence of the water content on both the concrete plate responses and void detection were studied. It should be noted that cases $\mathrm{W} 1$ and $\mathrm{W} 1 \mathrm{v}$ were the same as cases D3 and D3v.

Finally, in order to analyse the influence of void dimensions on the NDT results, a poor soil-concrete plate contact was designed with three different void sizes.

\subsection{Setup and Sensor Location}

The dimensions of the sand box were $0.6 \mathrm{~m} \times 0.6 \mathrm{~m} \times 0.9 \mathrm{~m}$. Four steel plates were connected with bolts on the bottom, back, left and right sides. A concrete plate with dimensions of $0.58 \mathrm{~m} \times 0.8 \mathrm{~m} \times 0.05 \mathrm{~m}$ was installed on the front side. The concrete plate surface required sanding to ensure a tight contact between the plate and the sensor base. Polystyrene foam pads were installed between the soil and steel plates to reduce the wave reflection from the steel boundaries. The research demonstrated that the boundary effect was the lowest when the thickness and width ratio of the elastic pads was between $2 \%$ and $4 \%$ [24]. Accordingly, the thickness of the pads was selected to be $0.02 \mathrm{~m}$. 
Table 2 lists the main tools or instruments used for soil sample preparation. In order to obtain uniform soil particles, according to the Standard for engineering classification of soil (GB/T 50145-2007) [25], the pore sizes of the test sieves were determined to be $0.5,0.25$ and $0.075 \mathrm{~mm}$, and finally, soils with sizes between 0.25 and $0.5 \mathrm{~mm}$ were used for the test. In order to change the soil density, a ramming hammer was used to ram the soil layer by layer, where the hammer mass was $6.5 \mathrm{~kg}$. Each drop height was maintained at $30 \mathrm{~cm}$. Furthermore, an electronic platform scale (manufactured by Huaying weighing instrument Co., Ltd, Yongkang, Zhejiang, China), tarpaulin, constant temperature oven (manufactured by Shuli Instrument Co., Ltd, Shanghai, China), weighting box and electronic balance (manufactured by Shenzhen Meifu Electronic Co., Ltd, Shenzhen, Guangdong, China) were employed during the soil sample preparation.

Table 3 lists the main equipment used for the dynamic NDT, including a dynamic hand hammer, accelerometer and an INV3062T high-precision portable data acquisition system. The data acquisition hardware was connected to a PC via a USB interface. All these instruments were calibrated prior to the test.

The accelerometer was bonded to the concrete plate surface. The impact location was $2 \mathrm{~cm}$ from the sensor. For the cases with a changing density and water content, the accelerometer was fixed at the centre of the concrete plate (Figure 3). By using the IE method, responses at the concrete plate centre were obtained.

Table 2. Main tools or instruments for soil sample preparation.

\begin{tabular}{|c|c|c|c|c|c|}
\hline $\begin{array}{c}\text { Tool/ } \\
\text { Instrument }\end{array}$ & Picture & Description & $\begin{array}{c}\text { Tool/ } \\
\text { Instrument }\end{array}$ & Picture & Description \\
\hline Test sieves & & $\begin{array}{c}\text { Sieve soil with } \\
\text { pore sizes of } \\
0.5,0.25 \text { and } \\
0.075 \mathrm{~mm}\end{array}$ & $\begin{array}{l}\text { Constant } \\
\text { temperature } \\
\text { oven }\end{array}$ & & $\begin{array}{c}\text { Dry soil and } \\
\text { measure water } \\
\text { content }\end{array}$ \\
\hline $\begin{array}{l}\text { Ramming } \\
\text { hammer }\end{array}$ & & Ram soil & Weighting box & & $\begin{array}{c}\text { Weight soil } \\
\text { samples for } \\
\text { water content } \\
\text { measurement }\end{array}$ \\
\hline $\begin{array}{c}\text { Electronic } \\
\text { platform scale }\end{array}$ & & $\begin{array}{l}\text { Weight and } \\
\text { measure soil } \\
\text { layer mass }\end{array}$ & $\begin{array}{l}\text { Electronic } \\
\text { balance }\end{array}$ & & $\begin{array}{l}\text { Weight and } \\
\text { measure soil } \\
\text { mass }\end{array}$ \\
\hline Tarpaulin & & $\begin{array}{l}\text { Encase soil to } \\
\text { ensure water } \\
\text { permeates } \\
\text { evenly into } \\
\text { soils }\end{array}$ & & & \\
\hline
\end{tabular}


Table 3. Main equipment for dynamic non-destructive testing (NDT).

\begin{tabular}{|c|c|c|c|c|}
\hline Equipment & Picture & Manufacturer & Model & Main Parameters \\
\hline $\begin{array}{l}\text { Dynamic hand } \\
\text { hammer }\end{array}$ & & $\begin{array}{c}\text { Dytran } \\
\text { Instruments, Inc., } \\
\text { Chatsworth, CA, } \\
\text { USA }\end{array}$ & $\begin{array}{l}\text { Dytranpulse }^{\mathrm{TM}} \\
\text { 5800B4T }\end{array}$ & $\begin{array}{l}\text { Hammer head weight: } \\
100 \mathrm{~g} \\
\text { Sensitivity: } 10 \mathrm{mV} / \mathrm{lbf} \\
\text { Measurement range: } \\
500 \mathrm{lbf} \\
\text { Maximum impact load: } \\
1000 \mathrm{lbf}\end{array}$ \\
\hline Accelerometer & & $\begin{array}{c}\text { Lance Technologies } \\
\text { Inc., Copley, OH, } \\
\text { USA }\end{array}$ & Lance LC0156A & $\begin{array}{l}\text { Measurement range: } \\
\quad 20 \mathrm{~g} \\
\text { Working frequency: } 0.1 \\
\text { to } 6000 \mathrm{~Hz} \\
\text { Resolution: } 0.02 \mathrm{mg}\end{array}$ \\
\hline Data acquisition & & $\begin{array}{c}\text { China Orient } \\
\text { Institute of Noise \& } \\
\text { Vibration, Beijing, } \\
\text { China }\end{array}$ & INV3062T & $\begin{array}{l}\text { Maximum sampling } \\
\text { frequency: } 51.2 \mathrm{kHz}\end{array}$ \\
\hline Laptop & & $\begin{array}{c}\text { Lenovo, Beijing, } \\
\text { China }\end{array}$ & Thinkpad & \\
\hline
\end{tabular}

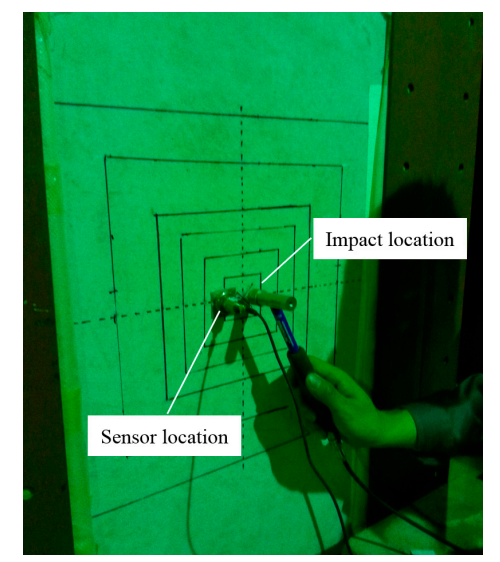

Figure 3. Impact location and layout of measuring points.

\section{Experimental Study}

\subsection{Soil Density Alteration}

Soils with three mass densities were tested, namely cases D1, D2 and D3, as listed in Table 1. When changing the density, the sand box was divided into nine parts from top to bottom and marked with a $10 \mathrm{~cm}$ height for each. For case D1, the soils were loaded nine times and each part of the soil was weighted. As the box volume was known, it was easy to calculate the bulk density, $\rho_{1}=1578 \mathrm{~kg} / \mathrm{m}^{3}$, and the densities $\rho_{2}$ and $\rho_{3}$ could be obtained by ramming.

Figure 4 illustrates the typical time histories of the three test cases with three different densities. It can clearly be seen that with an increase in density, the peak amplitude value decreased; furthermore, a smaller soil density induced faster attenuation. In order to quantify the attenuation trend, the number of threshold crossings, or simply "counts" in acoustic emission terminology, was examined [14,26]. The threshold of the waveform peak value was defined as $10 \%, 1 \%$ and $0.1 \%$ of the first peak value of the waveforms. The total number of threshold crossings can reflect the attenuation speed. If the threshold was set to be large, for example, $10 \%$, only larger oscillations were counted. For each case, the tests 
were repeated four times, and the results are shown in Figure 5. For larger densities, the number of threshold counts was smaller, i.e., the vibration attenuated faster. It can be concluded that if the density was large, the impedance difference between the soil and concrete was small, and accordingly, the reflection energy was weak.

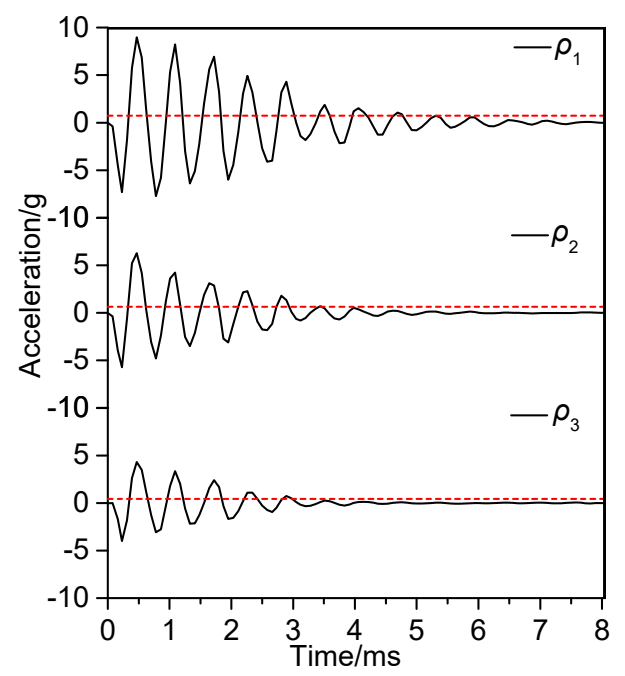

Figure 4. Acceleration waveforms for different density cases.
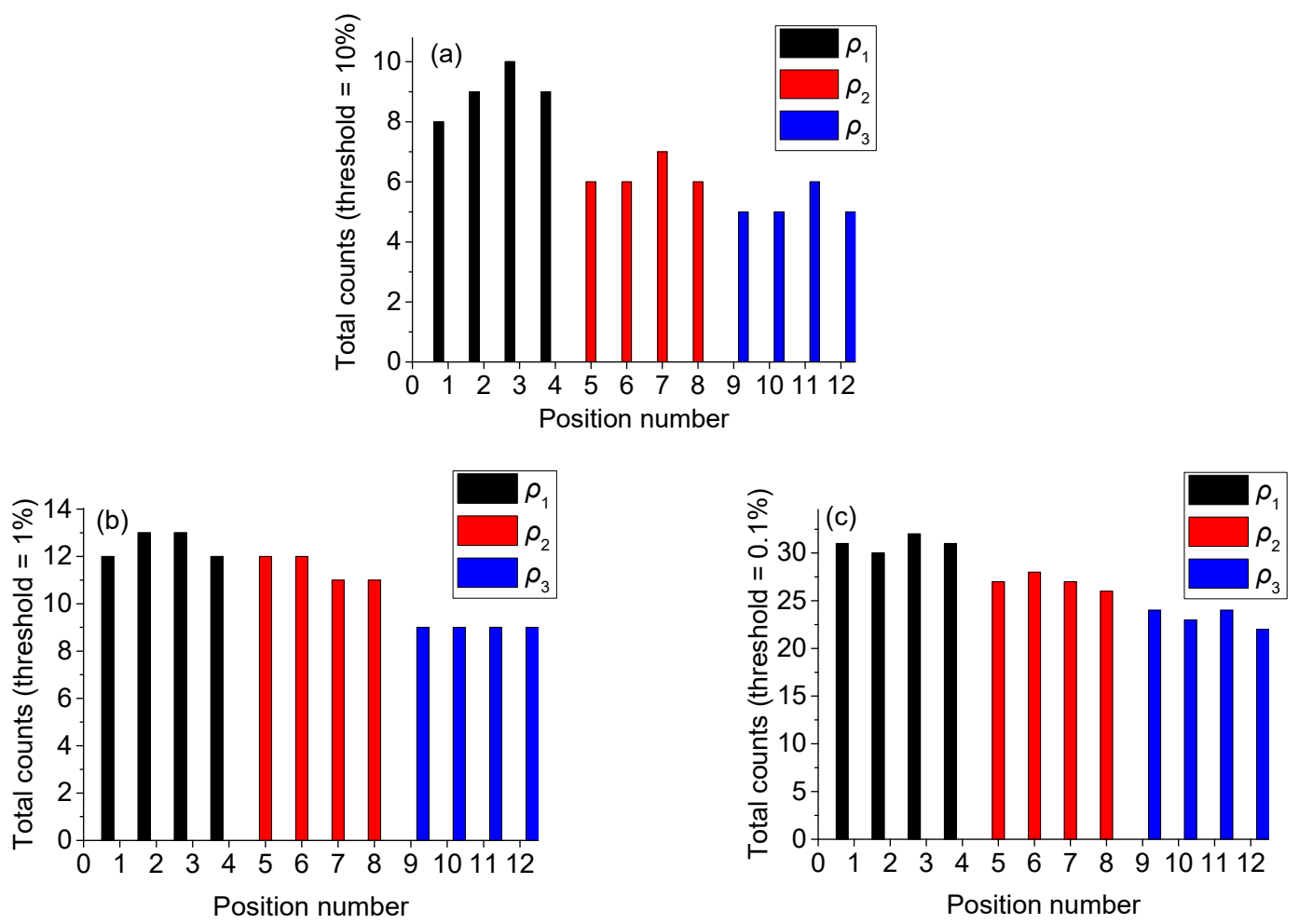

Figure 5. Number of counts for thresholds of (a) $10 \%$, (b) $1 \%$ and (c) $0.1 \%$ of the peak value.

In the following analysis, fractal theory was employed to calculate the box-counting dimensions of different vibration signals in the time domain. Fractal theory, proposed by Mandelbrot [27], is used to describe complex shapes, such as coastlines and rivers that cannot be described using Euclidean geometry. However, these complex systems should have the characteristic of self-similarity, such that the internal rules of them can be expressed using fractal theory. The vibration responses are random fractal signals fulfilling the criterion of statistical self-similarity [28]. 
The counting dimension is an important index of fractal theory used to describe the internal rules of complex shapes. The regular geometric space includes the point, line, plane and volume, with corresponding dimensions of $0,1,2$ and 3; nevertheless, the counting dimension is not integral. Within fractal theory, the box-counting dimension method is widely used because it is easier to be calculated. It can recognize the difference among various signals quantitatively. The box-counting dimension is obtained by covering the object using square boxes with side length $\delta$. To cover the unit square using a box-counting dimension, $N$ small square boxes with a side length $\delta$ are needed. The number of $N$ is calculated using:

$$
N=\left(\frac{1}{\delta}\right)^{2}
$$

For a unit square, the dimension $D$ is 2 , which can be calculated using:

$$
D=\frac{\log N}{-\log \delta} .
$$

If the fractal object has an irregular shape, the box-counting dimension can be calculated in the same way. However, it should be noted that the dimension may not be an integer. The acceleration vibration signal discussed in this study was an irregular curve that varied with time (Figure 6). In this case, the box-counting dimension is defined as:

$$
D=\lim _{\substack{\delta_{1} \rightarrow 0 \\ \delta_{2} \rightarrow 0}} \frac{\log N}{-\log \delta_{i}}
$$

where $i=1$ or 2 . The small boxes used to cover the signal have the dimensions of $\delta_{1} \times \delta_{2}$, of which, $\delta_{1}$ is the sampling time interval and $\delta_{2}$ is the smallest difference of the accelerations between two sampling points (non-zero). Because the vibration signals were discrete, the counting dimension $D$ was obtained as the slope of the linear regression of a series data $\left(-\log k_{j} \delta_{i}, \log N_{j}(j=1,2, \ldots)\right)$, instead of calculating the limit. $k_{j}$ is a constant that controls the size of the boxes $k_{j}\left(\delta_{1} \times \delta_{2}\right)$. However, in order to make the covering process meaningful, it should be noted that the constant $k_{j}$ is limited according to [29]:

$$
\left\{\begin{array}{l}
\delta_{1}<k_{j} \delta_{1}<\frac{\Delta T}{2} \\
\delta_{2}<k_{j} \delta_{2}<\frac{a_{\max }}{2}
\end{array},\right.
$$

where $\Delta T$ is the time internal between the peak value point and the adjacent zero value point (Figure 6), and $a_{\max }$ is the peak value of the acceleration.

The box-counting dimension expresses the covering level of the vibration signal and is between 1 and 2. In the present study, if the box-counting dimension is larger, the vibration signal may attenuate more slowly or dominate at a higher frequency range, and vice versa. 


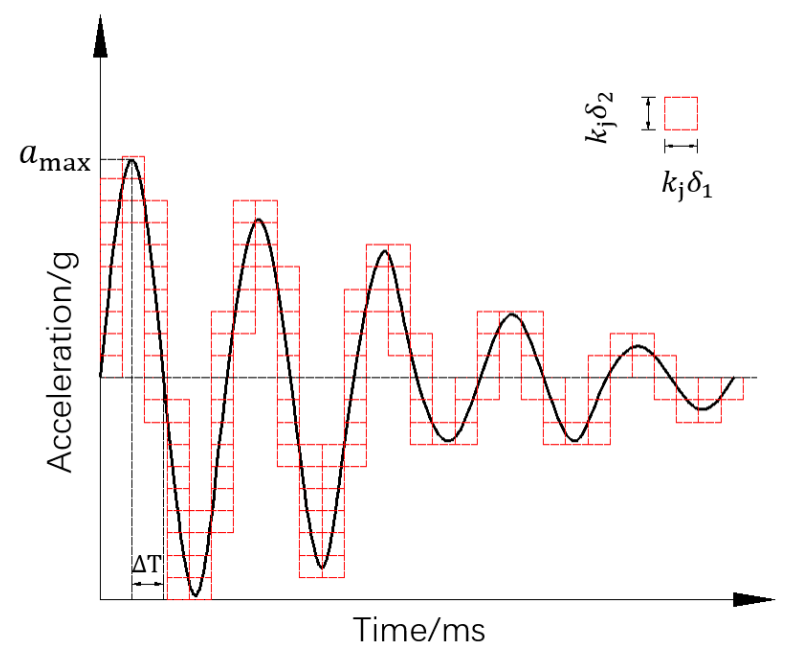

Figure 6. A vibration signal covered with small boxes.

Figure 7 illustrates the box-counting dimensions for different soil density cases. Each value was averaged using 10 useful data points. The counting dimension value increased with a decrease in soil density. For case D3, with the largest density, the existence of the void induced a sharp increase in the dimension, from 1.2601 to 1.3416 . Thus, the compactness between the soil and concrete plate played an important role in the counting dimension. Case D3 had the densest soil, and subsequently, the best compactness, while case D3v had the worst compactness due to the void's influence. The box-counting dimension can reflect the contact condition between the soil and concrete, and evaluate the void quantitatively. If the density is significantly altered, the void inspection results may be affected.

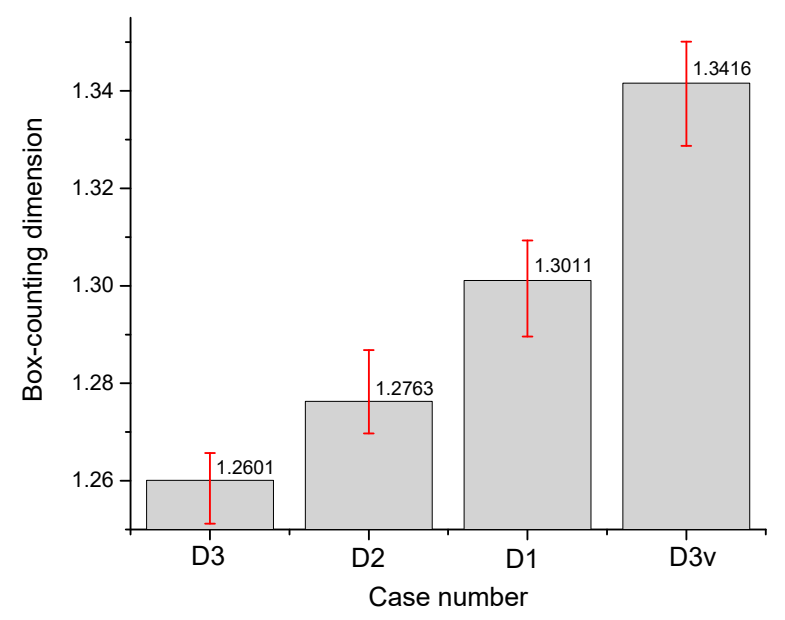

Figure 7. Fractal box-counting dimensions for different soil density cases.

The frequency spectrum can be calculated using a Fourier transform. Figure 8 illustrates the Fourier spectra for three different density cases, each of which was averaged using multiple signals. It can be observed that the dominant frequency was between 1640 and $1690 \mathrm{~Hz}$ for all cases. This frequency can be explained by the local resonance theory of a plate. Suppose the plate displacement $u(r)$ at location $r$ is [30]:

$$
u(r)=u_{0}\left(1-\frac{r^{2}}{a^{2}}\right)^{2},
$$


where $u_{0}$ is the displacement amplitude and $a$ is the affecting area of the impact load. The potential energy $W_{\text {pot }}$ and kinetic energy $W_{\text {kin }}$ can be expressed as [31]:

$$
\begin{aligned}
& W_{\text {pot }}=\frac{32 \pi D u_{0}^{2}}{3 a^{2}}+\frac{k \pi u_{0}^{2} a^{2}}{6}, \quad D=\frac{E h^{3}}{12\left(1-v^{2}\right)} \\
& W_{\text {kin }}=\frac{m u_{0}^{2}}{10}
\end{aligned}
$$

where $E, v, m$ and $h$ are the elastic modulus, Poisson's ratio, mass and thickness of the plate, respectively. By introducing the principle of energy equivalence, the equivalent mass and stiffness can be obtained. Finally, the first order of the local mode frequency can be calculated using:

$$
f_{0}=\frac{1}{2 \pi} \sqrt{\frac{192 D / a^{4}+3 k}{1.8 \rho h}},
$$

where $k$ is the equivalent supporting stiffness given to the plate by the soil.

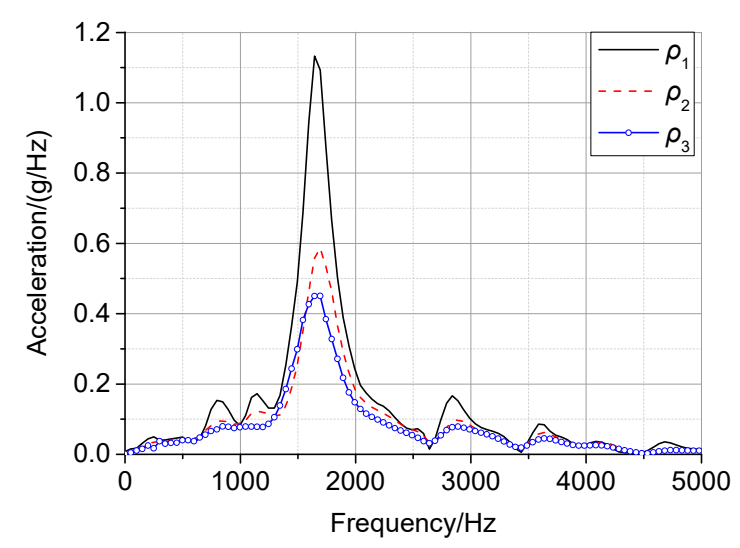

Figure 8. Acceleration frequency spectra for different density cases.

For the laboratory test, $E=3.2 \times 10^{10} \mathrm{~N} / \mathrm{m}^{2}, h=0.05 \mathrm{~m}, a=0.25 \mathrm{~m}, v=0.2, \rho=2300 \mathrm{~kg} / \mathrm{m}^{3}$ and $k=4 \times 10^{8} \mathrm{~N} / \mathrm{m}$; therefore, $D$ was calculated to be $3.472 \times 10^{5} \mathrm{~N} \cdot \mathrm{m}$; and finally the resonance frequency was calculated to be $1496 \mathrm{~Hz}$, which was close to the tested dominant frequency. The resonance frequency is mainly determined by the plate and soil. The void can only affect the amplitude but not the frequency of the resonance. The explanation matched with the test results.

With increasing density, the dominant frequency amplitude decreased. For case D1, peak values around 800, 1100 and $2800 \mathrm{~Hz}$ could also be observed. The energy was concentrated at certain frequencies compared to the other two cases. This was caused by the looser concrete-soil contact, which induced a more complex wave reflection at the interface.

In addition to Fourier spectrum analysis, wavelet transforms (WTs) were employed to perform time-frequency domain analysis, which provided more valuable visualised information. For the non-stationary signals, i.e., responses induced by impact loads, the frequency domain representation changes over time. Time-frequency domain analysis offers advantages over the frequency or time domain signal representations. Figure 9 illustrates the time-frequency spectra for three density cases, where the energy distribution of the acceleration responses can clearly be observed. With increasing density, the energy attenuation duration became shorter and the amplitude became smaller. Similar to the Fourier spectrum, peak values around 800, 1100 and $2800 \mathrm{~Hz}$ were observed more clearly for case D1 than the other two cases. Moreover, the vibration energy above $2800 \mathrm{~Hz}$ had a short duration, while the energies around 800 and $1100 \mathrm{~Hz}$ had a longer duration. 


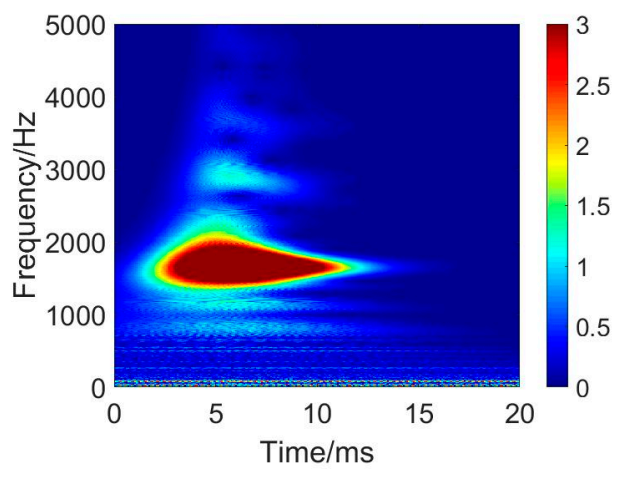

(a) $\rho_{1}$

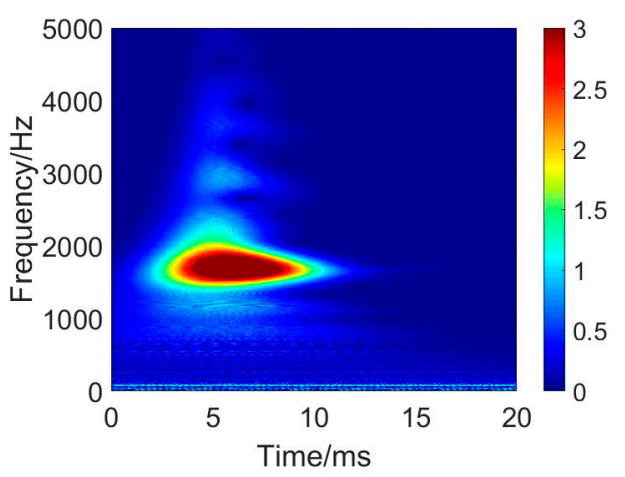

(b) $\rho_{2}$

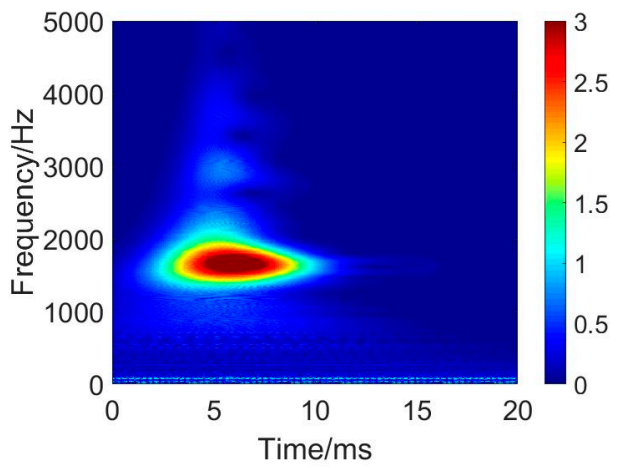

(c) $\rho_{3}$

Figure 9. Energy time-frequency distribution diagram for different density cases.

\subsection{Water Content Alteration}

Soils with three water contents were tested. For each water content, both non-void (case W1, W2 and W3) and void (cases W1v, W2v and W3v) conditions were considered, as listed in Table 1. For case $\mathrm{W} 1$, the soil was hammered to retain a soil height of $0.8 \mathrm{~m}$ in the box when the density was $\rho_{3}=1656 \mathrm{~kg} / \mathrm{m}^{3}$ and the natural water content was $\omega_{1}=0.3 \%$. In order to increase the water content, the soil was watered; then, the sand box was sealed with watertight tarpaulin. After $24 \mathrm{~h}$, the water content was measured with a constant temperature oven for five soil samples using $200 \mathrm{~g}$ aluminium boxes. Finally, soil with averaged water contents of $\omega_{2}=8.2 \%(\mathrm{~W} 2)$ and $\omega_{3}=15.3 \%(\mathrm{~W} 3)$ were obtained. Following the dynamic test for each soil water content case, the box with dimensions of $150 \mathrm{~mm} \times 150 \mathrm{~mm} \times 100 \mathrm{~mm}$ was embedded behind the concrete plate to model the void conditions. Thereafter, the dynamic tests were repeated.

\subsubsection{Vibration Response Changes with Water Content}

Figure 10 illustrates the typical time histories of three test cases with different water contents. It can clearly be observed that the amplitude for case W1 was the largest, while the waveforms for cases W2 and W3 were similar. Figure 11 illustrates the threshold numbers for $10 \%, 1 \%$ and $0.1 \%$ of the peak value. Compared with case W1, cases W2 and W3 had a smaller number of threshold counts; however, the difference between cases W2 and W3 was not obvious. This can be understood by noting that if the water content was large, the impedance difference between the soil and concrete was small, and accordingly, the reflection energy was weak. 


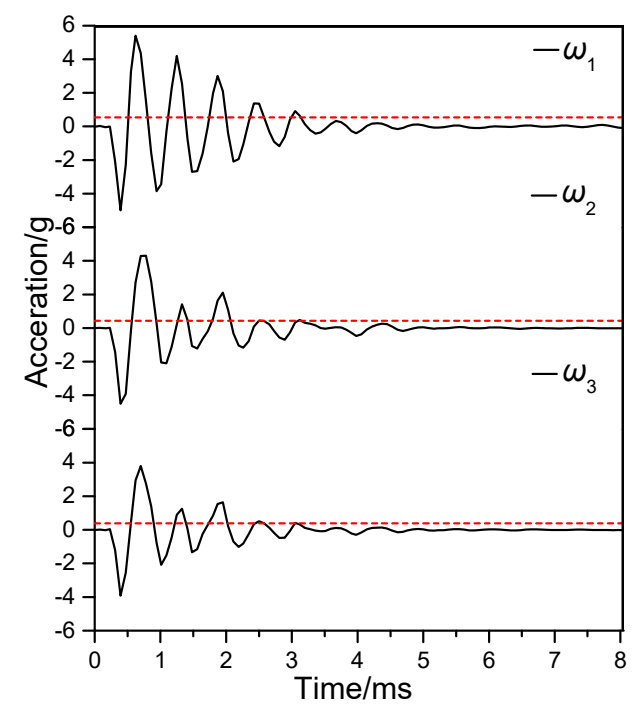

Figure 10. Acceleration waveforms for cases W1, W2 and W3.
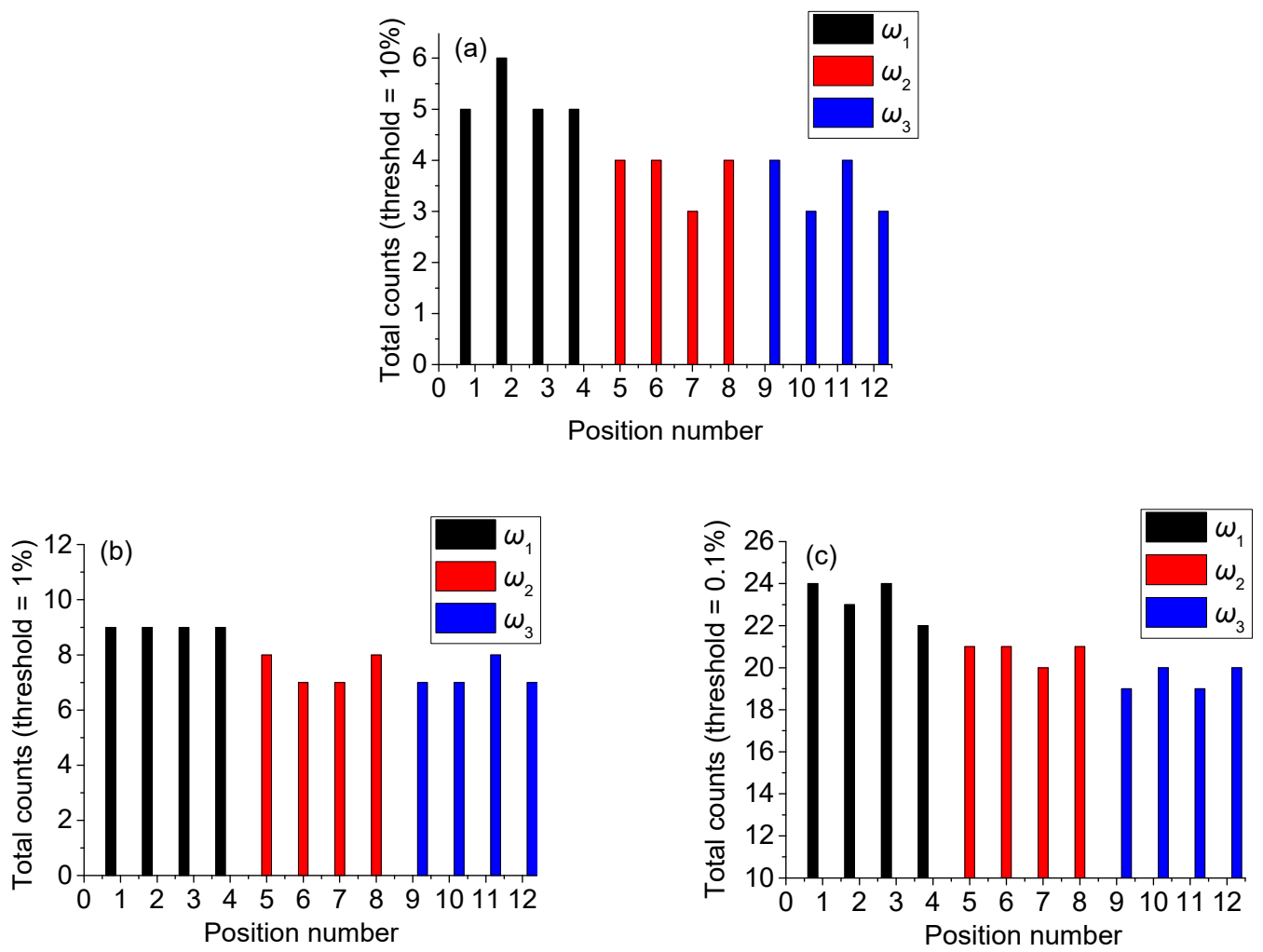

Figure 11. Number of counts for thresholds of (a) $10 \%$, (b) $1 \%$ and (c) $0.1 \%$ of peak value.

Using a Fourier transform, the frequency spectra for three different water content cases were obtained, as plotted in Figure 12. Each curve was averaged using multiple signals. It can be observed that the dominant frequency appeared at between 1640 and $1690 \mathrm{~Hz}$ for all cases. With increasing water content, the dominant frequency amplitude decreased. For cases W2 and W3, peak values around 850 and $1100 \mathrm{~Hz}$ were also observed. With increasing water content, the vibration energy shifted to lower frequencies. 


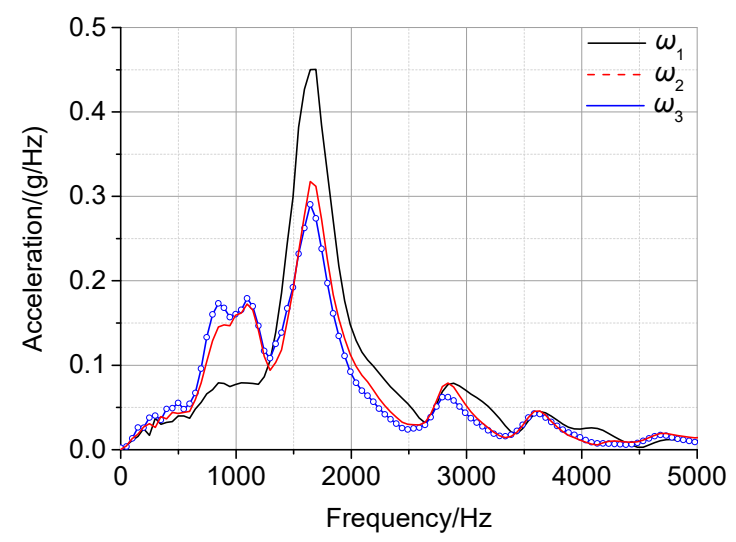

Figure 12. Acceleration frequency spectra for different water content cases.

\subsubsection{Vibration Responses Affected by Existence of Void}

Figure 13 illustrates the typical time histories of three test case groups for different water contents, with and without voids behind the concrete plate. Obvious differences were observed due to the existence of voids. Under the same water content conditions, the voids induced larger vibration amplitudes and longer attenuation durations.

Table 4 lists the average threshold numbers for $10 \%, 1 \%$ and $0.1 \%$ of the peak value under different test cases. For different water content cases, the number of threshold peaks for the void conditions was obviously larger than those for non-void conditions. That is, the existence of a void behind the concrete plate induced slower vibration attenuation. With increasing water content, the number of threshold peaks decreased for all cases, and the vibration attenuation became faster.

Table 4. Number of threshold peaks under different test cases.

\begin{tabular}{ccccccc}
\hline \multirow{2}{*}{$\begin{array}{c}\text { Water } \\
\text { Content }\end{array}$} & \multicolumn{2}{c}{$\begin{array}{c}\text { Threshold of } \mathbf{1 0 \%} \text { of Peak } \\
\text { Value }\end{array}$} & $\begin{array}{c}\text { Threshold of } \mathbf{1 \%} \text { of Peak } \\
\text { Value }\end{array}$ & \multicolumn{2}{c}{$\begin{array}{c}\text { Threshold of } \mathbf{0 . 1 \%} \text { of Peak } \\
\text { Value }\end{array}$} \\
\cline { 2 - 7 } & Without Void & With Void & Without Void & With Void & Without Void & With Void \\
\hline$\omega_{1}=0.3 \%$ & 5.3 & 8.5 & 9.0 & 13.3 & 23.3 & 33.0 \\
\hline$\omega_{1}=8.2 \%$ & 3.8 & 8.3 & 7.5 & 13.0 & 20.8 & 32.0 \\
\hline$\omega_{1}=15.3 \%$ & 3.5 & 8.3 & 7.3 & 12.5 & 19.5 & 30.5 \\
\hline
\end{tabular}

According to Equation (1), fractal analysis can also be applied to the waveforms in Figure 13. Figure 14 shows the box-counting dimensions for different water content cases. Each value was averaged using 10 useful data points. For both the void and non-void conditions, with increasing water content, the counting dimension value decreased. Nevertheless, compared to the non-void conditions, the dimension alteration was not obvious. Furthermore, for each water content case, the existence of the void induced a sharp increase in the dimensions. 

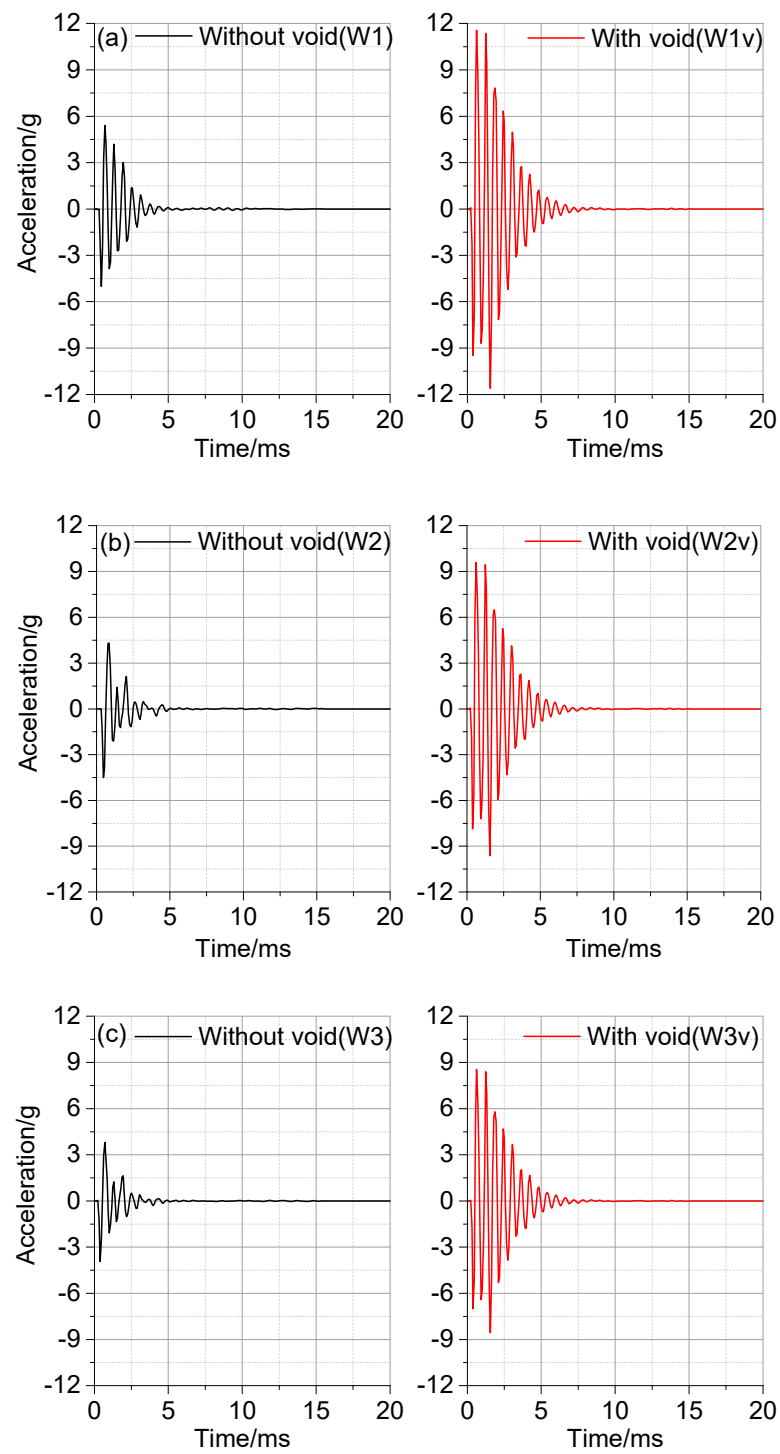

Figure 13. Typical acceleration waveforms for void and non-void conditions for different water content cases: (a) cases W1 and W1v, (b) cases W2 and W2v and (c) cases W3 and W3v.

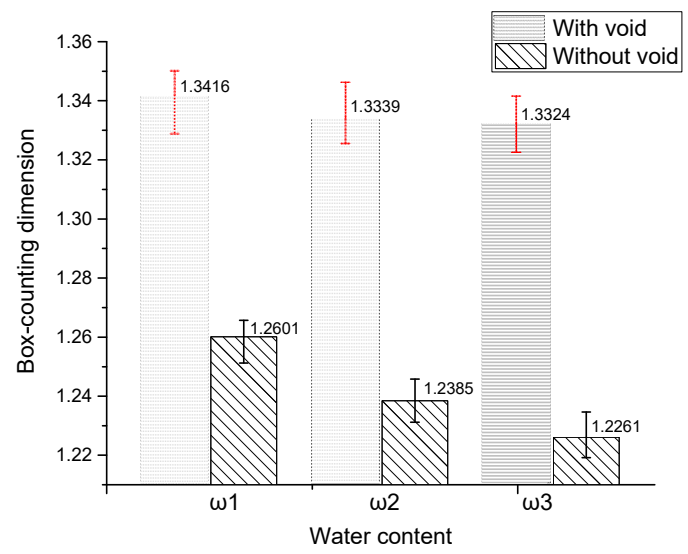

Figure 14. Fractal box-counting dimensions for different water content cases.

In summary, the box-counting dimension could effectively evaluate the void quantitatively, and alteration of the water content had little influence on the void inspection result. 
Figure 15 illustrates the typical Fourier spectra of three test case groups for different water contents, with and without voids behind the concrete plate. Under different water content conditions, the void always induced a dominant frequency at between 1640 and $1690 \mathrm{~Hz}$. That is, the void could cause wave reflection and energy concentration in the frequency domain. Moreover, alteration of the water content had little effect on void detection.
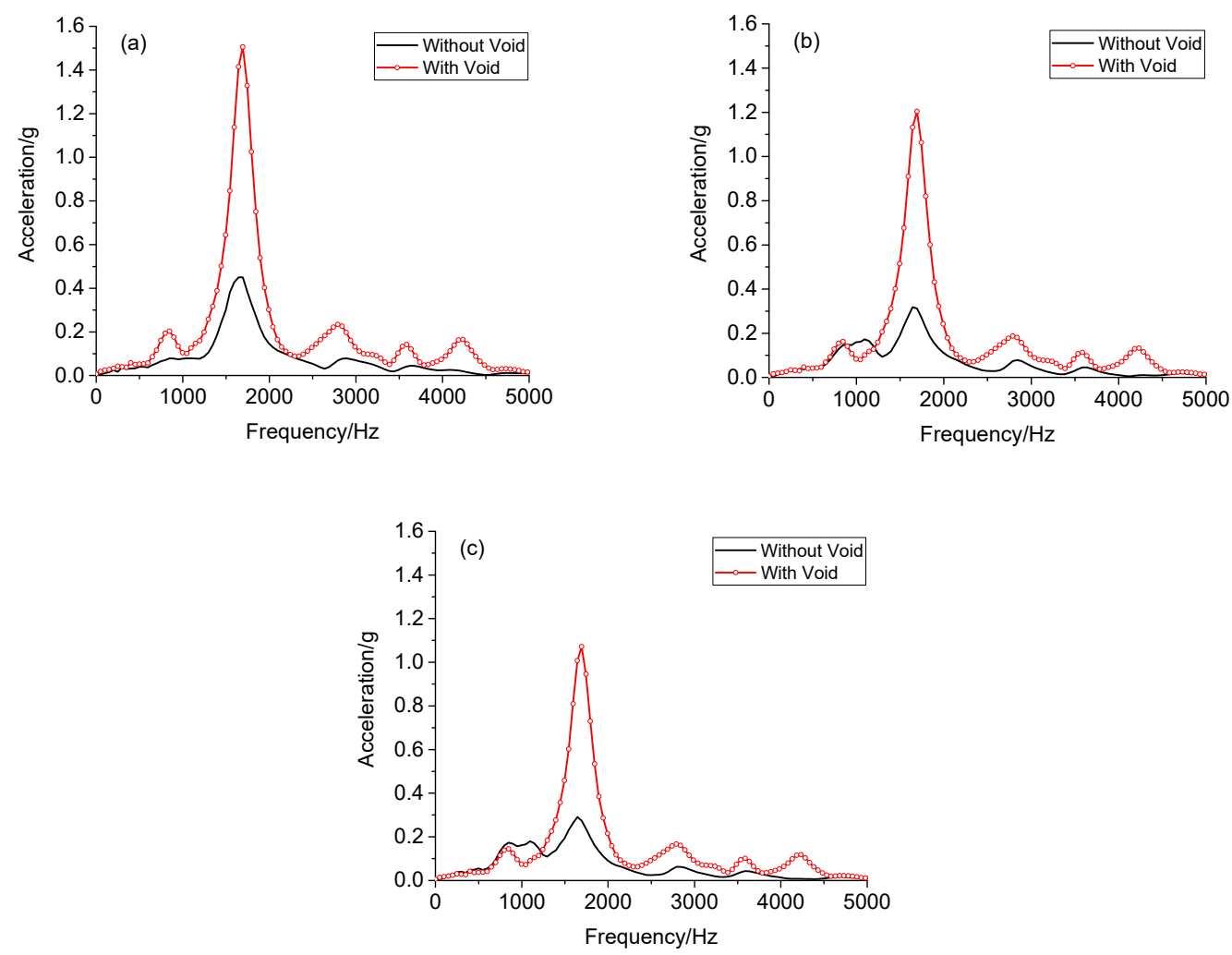

Figure 15. Typical frequency spectra of void and non-void conditions for different water content cases: (a) cases W1 and W1v, (b) cases W2 and W2v and (c) cases W3 and W3v.

Figure 16 illustrates the time-frequency spectra for three water content cases with and without voids by using wavelet transforms. The energy distribution of the acceleration responses were clearly observed. Figure 16a,c,e demonstrate that with increasing water content, the energy attenuation duration became shorter, the frequency distribution became wider and the amplitude became smaller. Similar to the Fourier spectrum, peak values around 800 to $1100 \mathrm{~Hz}$ were observed more clearly for cases W2 and W3 than for case W1. Furthermore, the energy around 800 and $1100 \mathrm{~Hz}$ has a longer duration. Comparing (a), (c) and (e) with (b), (d) and (f) of Figure 16, it can clearly be observed that the existence of voids induced a greater vibration energy concentration and a longer attenuation time. The results indicate that the time-frequency spectrum provided effective visual inspection for void detection but was not adequate for reliable quantification purposes. 


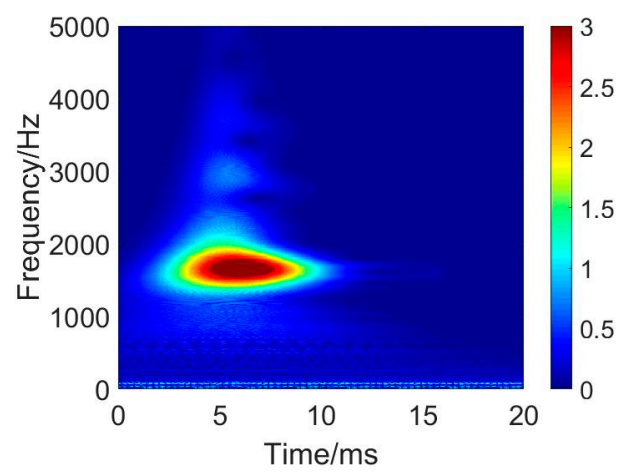

(a) Case W1

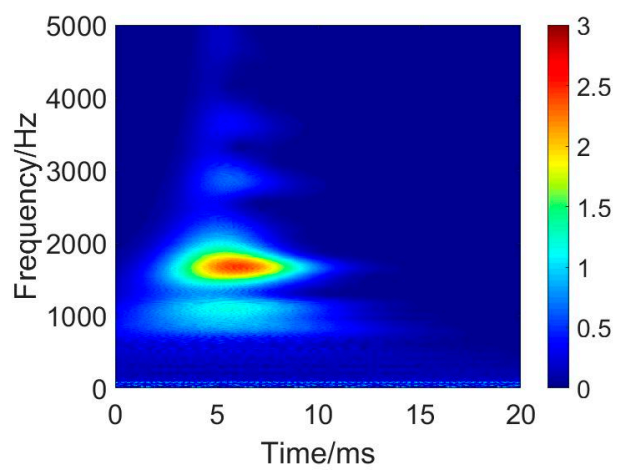

(c) Case W2

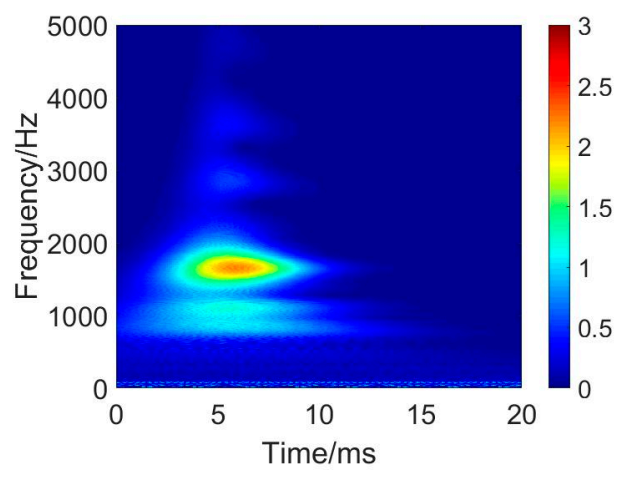

(e) Case W3

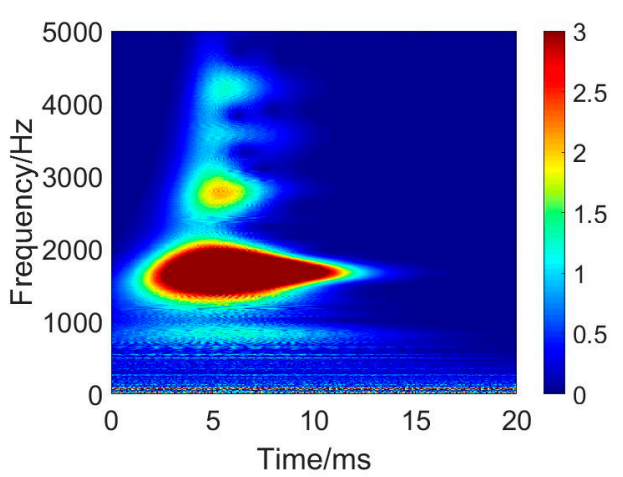

(b) Case W1v

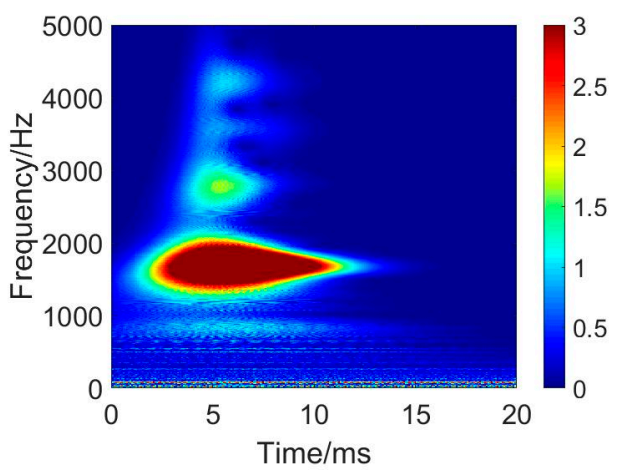

(d) Case W2v

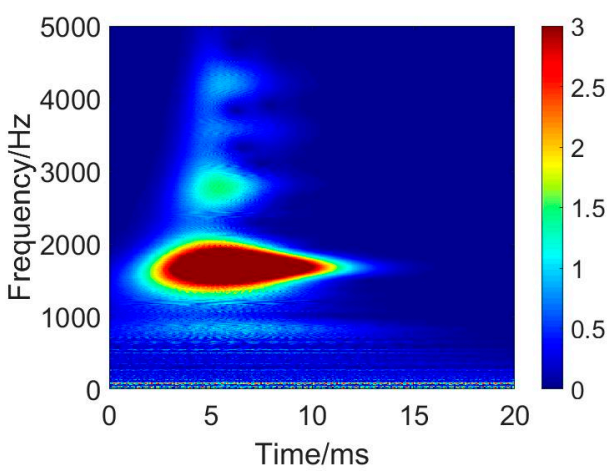

(f) Case W3v

Figure 16. Energy time-frequency distribution diagram for different water content cases.

\subsection{Void Size Alteration}

The void size is another important factor that affects NDT results. During NDT in practice, the void location is unknown; thus, the influence of the distance between the impact and detection points should also be taken into account. Accordingly, for the changing void size cases, the impact and sensor locations were moved along numbered measuring points (Figure 17) to aid in analysing the void size influence and its impact areas. In Figure 17, the distance between neighbouring points is $2.5 \mathrm{~cm}$. In order to describe the void size influence quantitatively, only the box-counting dimension analysis is presented in this sub-section. 


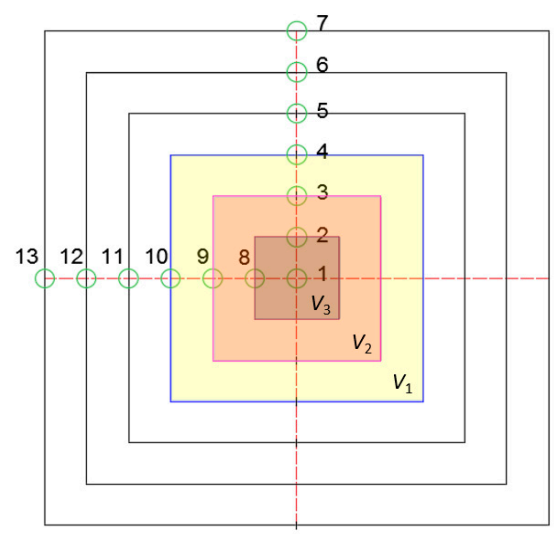

Figure 17. Numbering of measuring points.

As indicated in Table 1, the soil density was maintained at $\rho_{3}=1656 \mathrm{~kg} / \mathrm{m}^{3}$ and the water content was $\omega_{1}=0.3 \%$, and three different void sizes were designed: $V_{1}=150 \times 150 \times 100 \mathrm{~mm}^{3}$ (case V1), $V_{2}=100 \times 100 \times 100 \mathrm{~mm}^{3}$ (case V2) and $V_{3}=50 \times 50 \times 100 \mathrm{~mm}^{3}$ (case V3). Empty boxes of three different sizes were pre-embedded behind the plate, where the areas were marked with different colours (Figure 17).

For case V1, the box-counting dimension values along the vertical and horizontal measurement lines are plotted in Figure 18. It can be seen that within the plate area behind where the void is located, the dimension value remained stable; however, at the void area edge (points 4 and 10), the dimension values decreased sharply. Moreover, the values continued to decrease along the measurement lines. The values at points 7 and 13 were already similar to those of the non-void condition (case D3, see Figure 7).
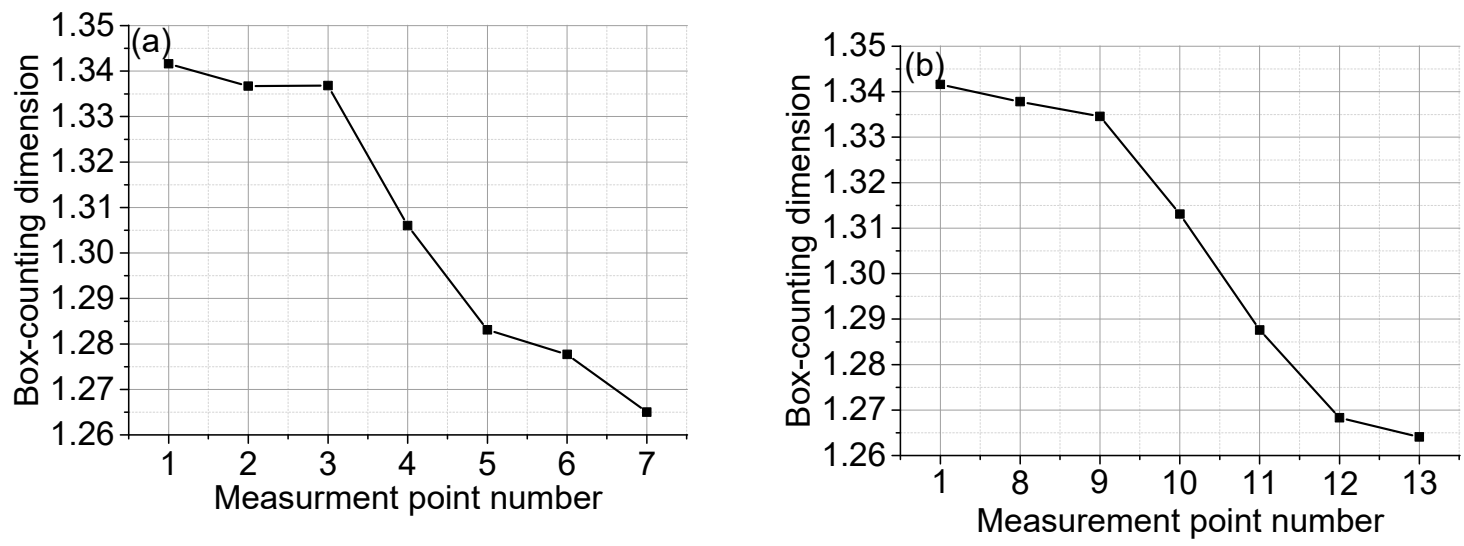

Figure 18. Box-counting dimensions for case V1: (a) along the vertical measurement line and (b) along the horizontal measurement line.

For cases V2 and V3, the values of the box-counting dimensions along two orthogonal directions are plotted in Figures 19 and 20, respectively, where similar results can be observed. At the void area edge (points 3 and 9 for case V2; points 2 and 8 for case 3), the dimension values decreased sharply. Moreover, the values continued to decrease along the measurement lines. The values at points 6 and 12 (for case V2) or points 5 and 11 (for case V3) remained stable and were already similar to those of the non-void condition (case D3, see Figure 7).

Figure 21 illustrates that the box-counting dimension varied with the void size for different measuring points. Generally, the dimension values decreased with the void size, but it was not obvious when the measuring point was far away from the void centre. 

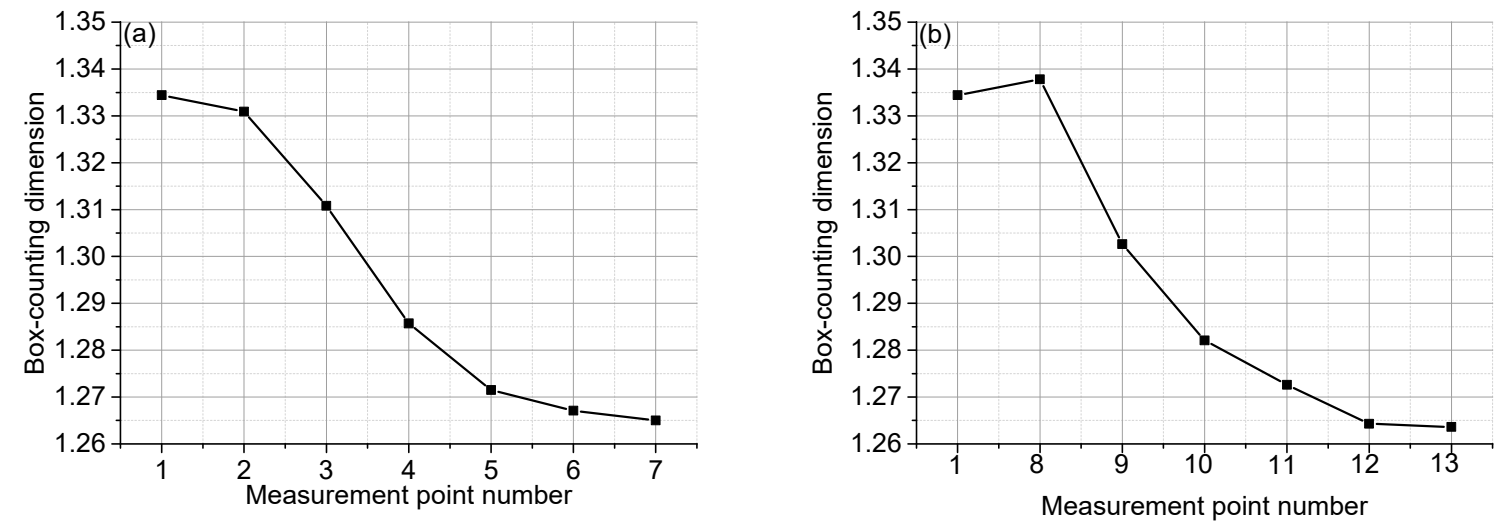

Figure 19. Box-counting dimensions for case V2: (a) along the vertical measurement line and (b) along the horizontal measurement line.
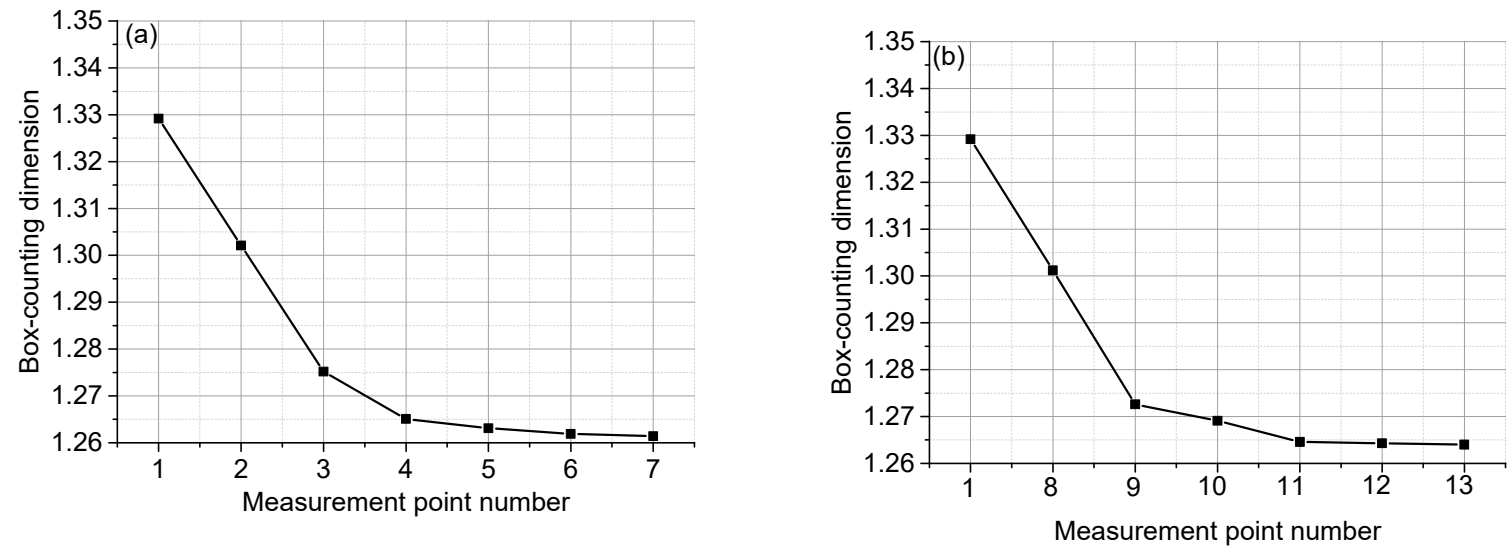

Figure 20. Box-counting dimensions for case V3: (a) along the vertical measurement line and (b) along the horizontal measurement line.

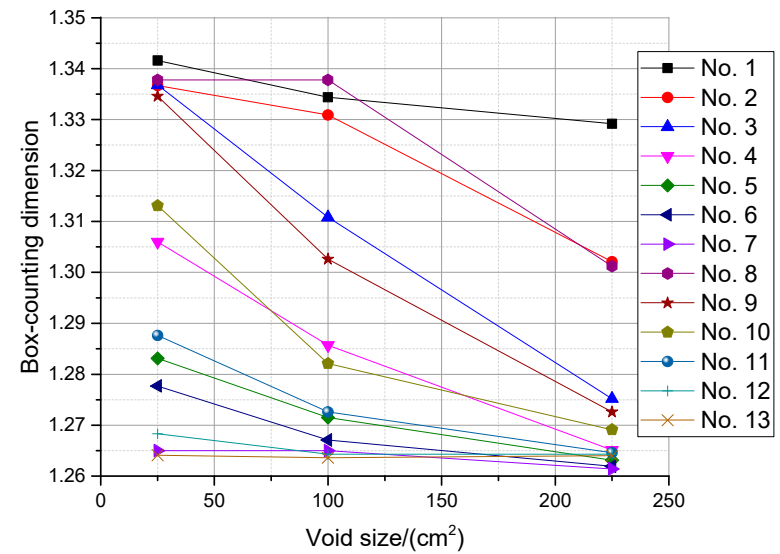

Figure 21. Box-counting dimension varied with the void size of different measuring points.

Accordingly, it is suggested that the orthogonal measurement lines should be plotted during the practice test. The impact and measurement points should be moved and the box-counting dimensions should be calculated for the vibration signals. If the dimension value is obviously enlarged, a potential void may exist behind the concrete structure. 


\section{Numerical Analysis}

\subsection{FE Model and Calibration}

As changing the soil parameters is time consuming and sometimes challenging, an FE model was built using the software ABAQUS, and then the soil parameters and influences were considered with further cases. In order to compare the numerical and tested results, the model dimensions were the same as those of the sand box used in the laboratory test. Due to symmetry, only half a sand box was built in the model (Figure 22). The soil and concrete plate were modelled using a linear reduced integral solid element C3D8R with a meshing size of $0.01 \mathrm{~m}$.
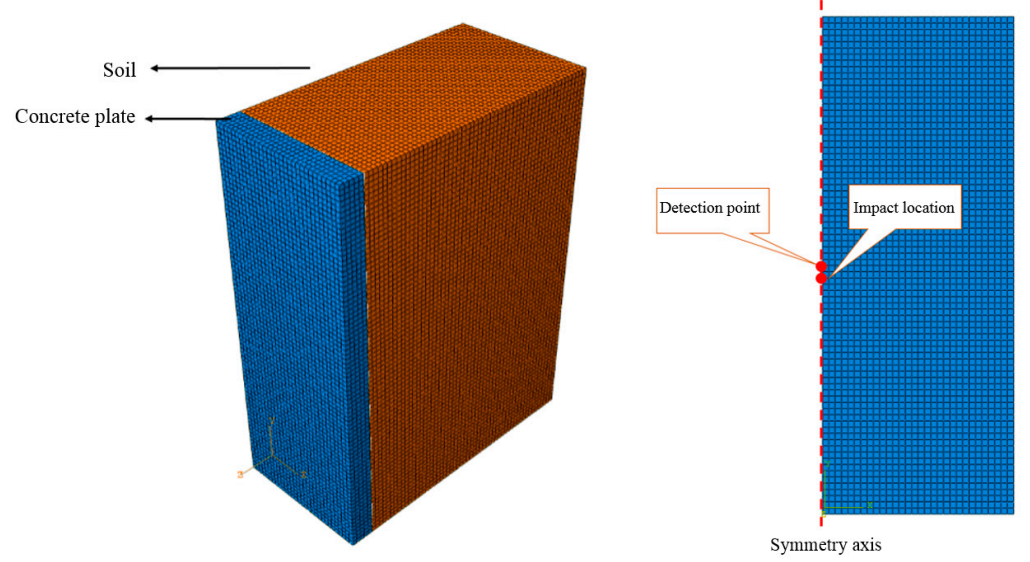

Figure 22. Finite element (FE) model.

The soil parameters were varied for the different cases. The concrete had a P-wave velocity of $4000 \mathrm{~m} / \mathrm{s}$, S-wave velocity of $2236 \mathrm{~m} / \mathrm{s}$, Poisson's ratio of 0.2 and density of $2400 \mathrm{~kg} / \mathrm{m}^{3}$.

Rayleigh damping was employed. The damping matrix $C$ is defined as a linear superposition of the mass matrix $M$ and stiffness matrix $K$ with coefficients $\alpha$ and $\beta$. The two coefficients can only be defined by the damping ratio of soils and analysis frequencies. In the model, the constant damping ratio of the soil was 0.3 ; therefore, the coefficients could finally be calculated as being $\alpha=1 \times 10^{-6}$ and $\beta=5 \times 10^{-4}$.

In order to prevent vibration wave reflection on the boundaries, infinite elements were applied to the three sides of the 3D dynamic model and fixed boundaries were applied at the bottom.

A half-sine pulse with a peak value of $600 \mathrm{~N}$ and time duration of $0.4 \mathrm{~ms}$ (Figure 23) was applied at the plate centre to model the impact load.

As shown in Figure 22, the detection point was at the plate centre, and the impact location was first located $2 \mathrm{~cm}$ below this. When analysing the void size and influence areas, the locations of the impact and detection points were moved along the vertical and horizontal axes.
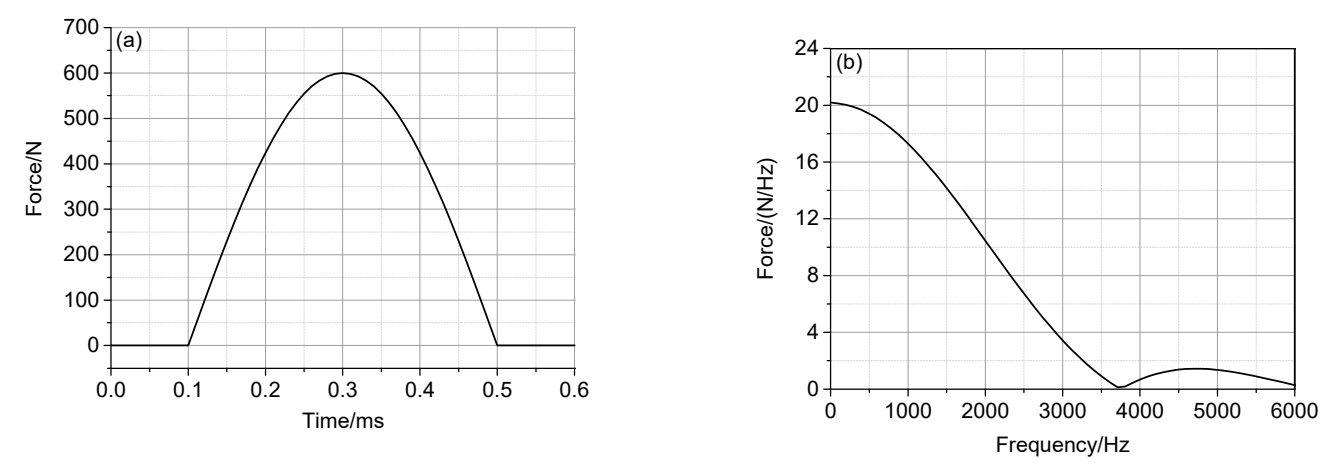

Figure 23. (a) Time history and (b) Fourier spectrum of the applied pulse force. 
The vibration response of the test case D3 was used for the FE model calibration. A comparison of the time history and Fourier spectrum is illustrated in Figure 24. It can be concluded that the test and FE results were generally well matched, particularly in the time domain. Due to the energy attenuation at high frequencies when using the hand hammer and the second peak amplitude of the half-sine signal (Figure 23), the difference was found to be between 4000 and $6000 \mathrm{~Hz}$.
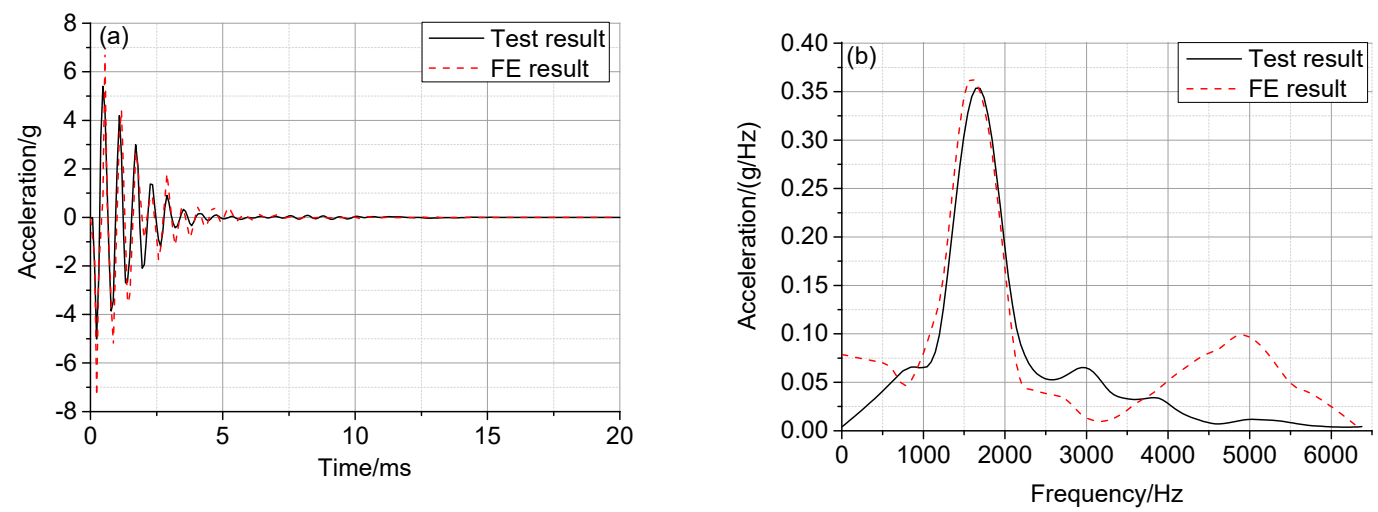

Figure 24. Comparison of FE and tested results in (a) time domain and (b) frequency domain.

\subsection{Parameter Analysis}

\subsubsection{Void Influence}

First, the void influence on the vibration response was analysed. In the FE model, the soil had a Young's modulus of $0.8 \mathrm{GPa}$, Poisson's ratio of 0.24 and density of $1600 \mathrm{~kg} / \mathrm{m}^{3}$. A void with dimensions of $16 \mathrm{~cm} \times 16 \mathrm{~cm} \times 10 \mathrm{~cm}$ was considered. The results obtained were similar to those of the tests (Figure 25). If a void existed behind the plate, the vibration amplitude was larger and the vibration duration was longer. By calculating the box-counting dimension, the value was determined to be 1.2569 for the non-void condition and 1.2976 for the void condition.
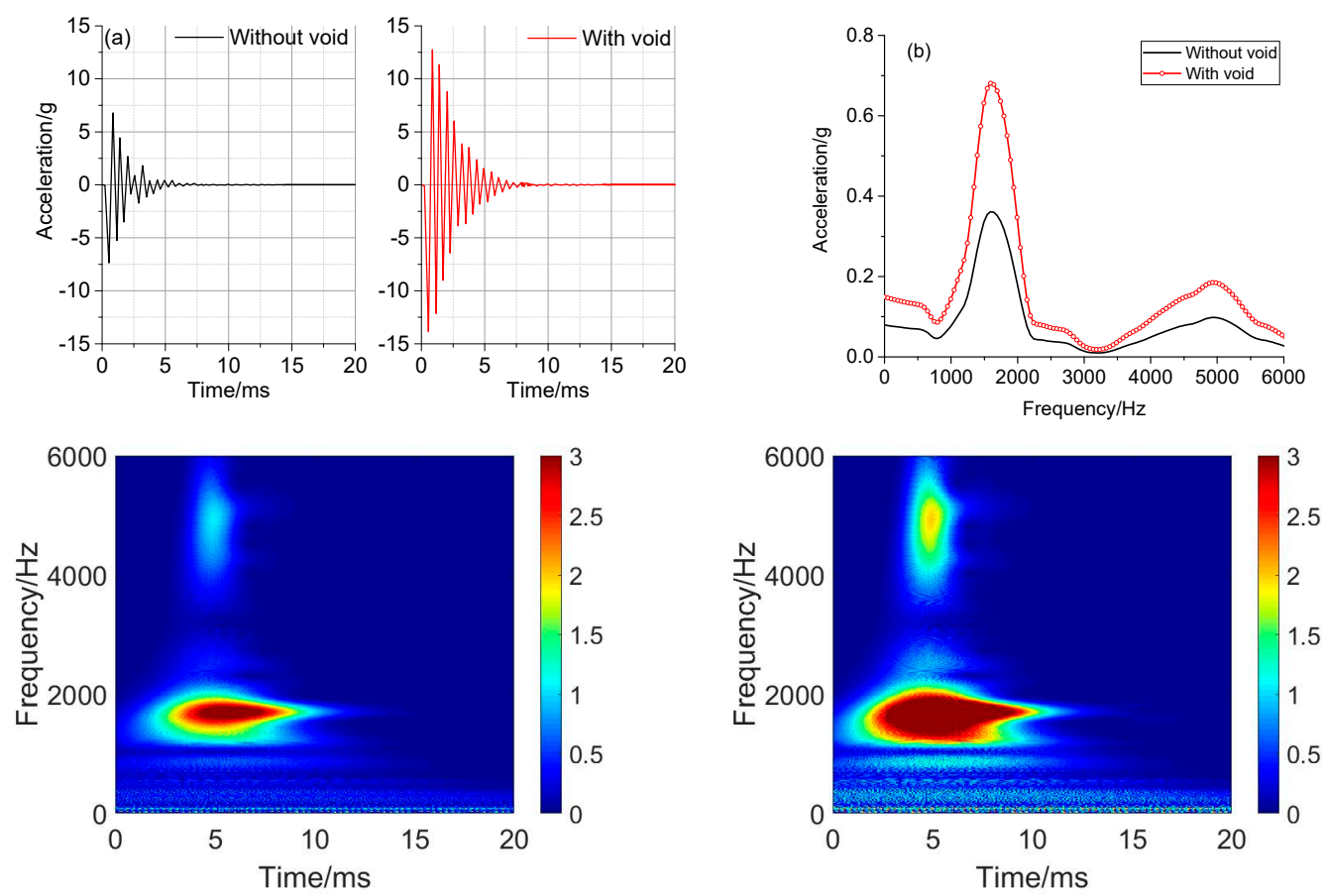

(c) Without void (left) and with void (right)

Figure 25. Void influence on vibration responses in (a) time domain, (b) frequency domain and (c) time-frequency domain. 


\subsubsection{Soil Parameters Influence}

Next, the influence of the soil parameters was analysed. The basic soil parameters were maintained the same as those used in Section 4.2.1. Only one variable was changed at a time. The density varied between 1500 and $2000 \mathrm{~kg} / \mathrm{m}^{3}$, Young's modulus between 0.2 and $1.0 \mathrm{GPa}$ and Poisson's ratio between 0.2 and 0.4 .

Figures 26 and 27 illustrate the varying values of the box-counting dimension and peak acceleration in the time history with three different soil parameters.
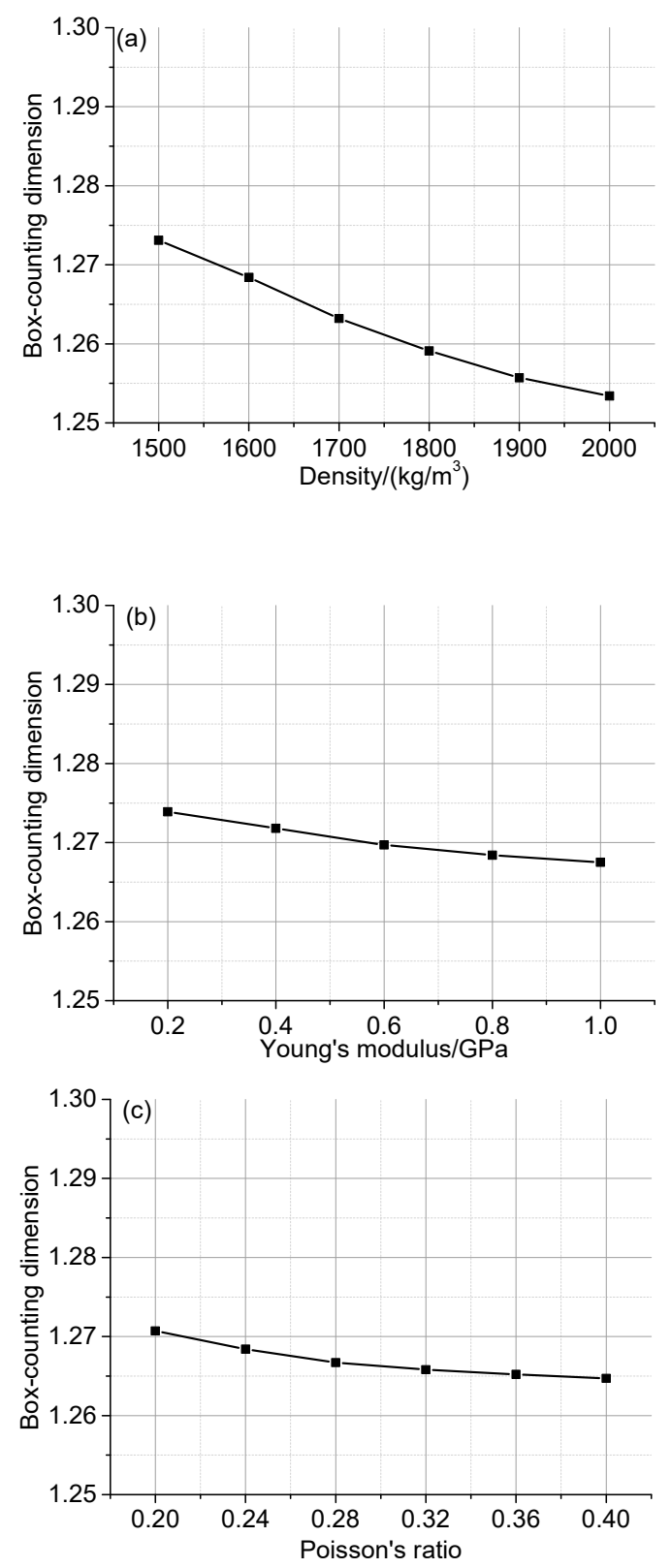

Figure 26. Values of box-counting dimensions varying with (a) density, (b) Young's modulus and (c) Poisson's ratio. 

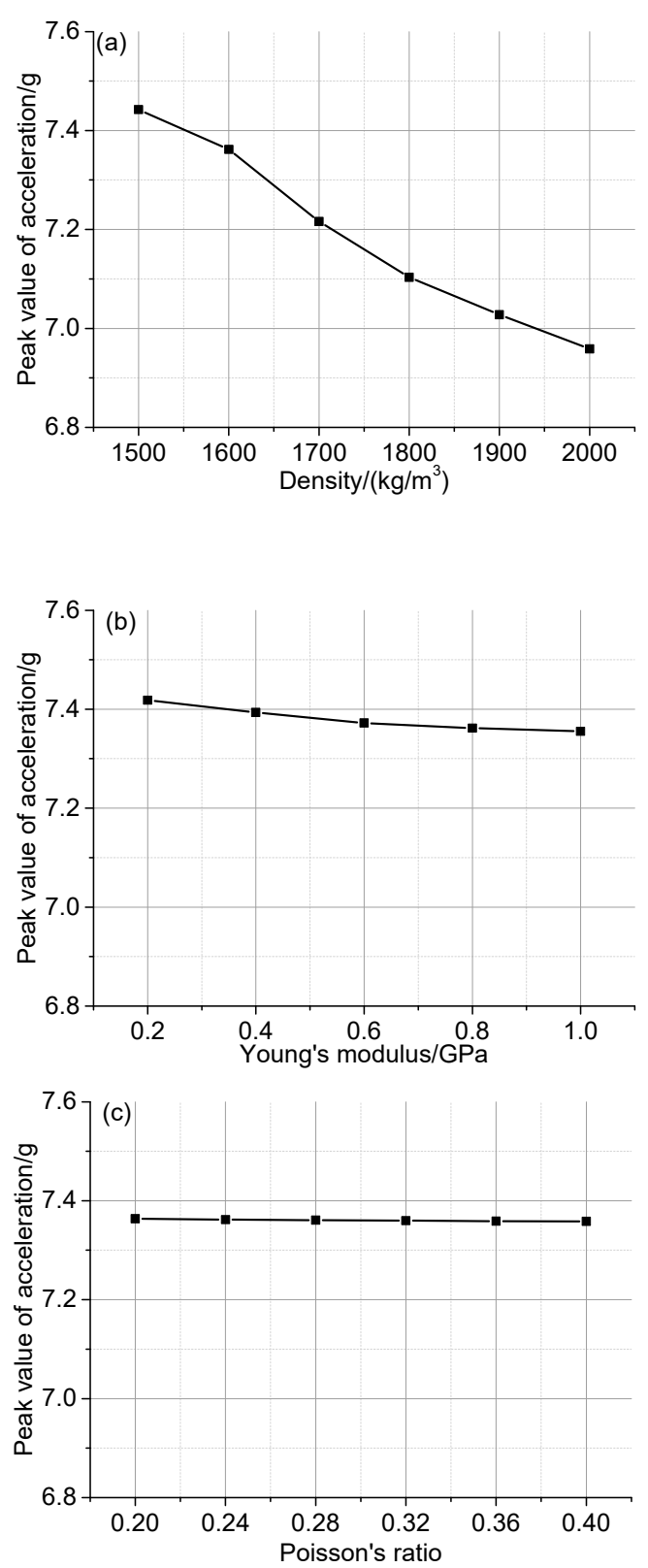

Figure 27. Peak acceleration value in time history varying with (a) density, (b) Young's modulus and (c) Poisson's ratio.

With increasing density, both the box-counting dimension and peak acceleration decreased sharply. Compared to the dimension value of 1.2976 for the void condition, density had a certain amount of influence on void detection. With an increasing Young's modulus, both the box-counting dimension and peak acceleration decreased slowly. Compared to the dimension value for the void condition, Young's modulus had a small influence on void detection. Poisson's ratio had the smallest effect on both values and almost no influence on void detection.

\subsubsection{Void Size Influence}

Finally, three void sizes were simulated: a large size of $16 \times 16 \times 10 \mathrm{~cm}^{3}$, medium size of $12 \times 12 \times 10 \mathrm{~cm}^{3}$ and small size of $6 \times 6 \times 10 \mathrm{~cm}^{3}$.

The impact location was maintained at the plate centre and the detection point was moved far away from the impact point. The box-counting dimension values for three void sizes are plotted in Figure 28. It can be seen that the largest box-counting dimension values appeared within the void 
areas; at the edge of the void areas, the values decreased sharply, until finally, the dimension values remained stable. Beyond twice the void dimension, it became difficult to locate the void.

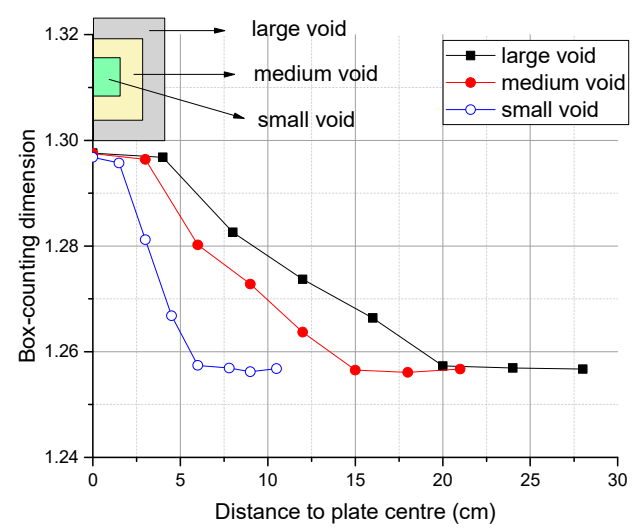

Figure 28. Box-counting dimensions at different detection points for three void sizes.

\section{Conclusions}

The following conclusions can be drawn from this study:

(1) A comprehensive analysis of vibration responses in the time, frequency and time-frequency domains was useful for void detection, and the box-counting dimensions were useful for quantitative evaluation of the void.

(2) With increasing soil density and water content, the acceleration response of the concrete slab decreased. Soils with a large density differences had a certain influence on the void detection, while changing the water content had little effect.

(3) By calculating the box-counting dimensions of the vibration responses, the value was found to be stable within the area where the void existed behind the tunnel. When the detection point was beyond twice the void dimension, it became difficult to locate the void.

(4) Using numerical simulation, the change in soil density and Young's modulus had some influence on void condition detection, while a change in Poisson's ratio had little effect.

Author Contributions: Formal analysis, C.N.; funding acquisition, H.Z.; investigation, R.C. and C.N.; methodology, M.M. and W.L.; software, H.Z.; supervision, W.L.; writing—review and editing, M.M. and R.C.

Funding: This research was funded by the Fundamental Research Funds for the Central Universities (grant number 2018JBM036) and the Beijing Natural Science Foundation (grant number 3184047).

Conflicts of Interest: The authors declare no conflict of interest. The funders played role in the design of the study, the collection of the results or the decision to publish the results.

\section{References}

1. Zhang, S.L. Study on Health Diagnosis and Technical Condition Assessment for Tunnel Lining Structure; Beijing Jiaotong University: Beijing, China, 2012.

2. Ni, S.H.; Lehmann, L.; Charng, J.-J.; Lo, K.-F. Low-strain integrity testing of drilled piles with high slenderness ratio. Comput. Geotech. 2006, 33, 283-293. [CrossRef]

3. Sansalone, M.S.W. Impact-Echo Nondestructive Evaluation of Concrete and Masonry; Bullbreier Press: Ithaca, NY, USA, 1997.

4. Lu, Z.T.; Wang, Z.L.; Liu, D.J. Study on low-strain integrity testing of pipe-pile using the elastodynamic finite integration technique. Int. J. Numer. Anal. Methods Geomech. 2013, 37, 536-550. [CrossRef]

5. Lin, S.K.; Lin, Y.; Hsu, K.-T.; Yen, T. Use of the normalized impact-echo spectrum to monitor the setting process of mortar. NDT E Int. 2010, 43, 385-393. [CrossRef]

6. Cheng, C.C.; Yu, C.-P.; Liou, T. Evaluation of interfacial bond condition between concrete plate-like structure and substrate using the simulated transfer function derived by IE. NDT E Int. 2009, 42, 678-689. [CrossRef] 
7. Ma, M.; Liu, J.; Ke, Z.; Gao, Y. Bearing Capacity Estimation of Bridge Piles Using the Impulse Transient Response Method. Shock Vib. 2016, 2016. [CrossRef]

8. Davis, A.G.; Lim, M.K.; Petersen, C.G. Rapid and economical evaluation of concrete tunnel linings with impulse response and impulse radar non-destructive methods. NDT E Int. 2005, 38, 181-186. [CrossRef]

9. Ni, S.H.; Lo, K.-F.; Lehmann, L.; Huang, Y.-H. Time-frequency analyses of pile-integrity testing using wavelet transform. Comput. Geotech. 2008, 35, 600-607. [CrossRef]

10. Olson, L.D. Dynamic Bridge Substructure Evaluation and Monitoring; US Federal Highway Administration: Washington, DC, USA, 2005.

11. Olson, L.D.; Sack, D.A.; Ii, K.H.S.; Buchinski, K.W. Stress-wave nondestructive testing of tunnels and shafts. Transp. Res. Rec. 1993, 1415, 88-94.

12. Guevremont, P. Using NDT for thickness measurement of shotcrete rock support systems in underground mines. Am. Inst. Phys. 2000, 509, 1701-1707.

13. Bosela, P.A.; Lek-Udom, S.; Mullangi, S.; Delatte, N. Field Comparison of NDE Methods for Tunnel Condition Assessment. In Proceedings of the Fourth Forensic Engineering Congress, Cleveland, OH, USA, 6-9 October 2006.

14. Aggelis, D.G.; Shiotani, T.; Kasai, K. Evaluation of grouting in tunnel lining using impact-echo. Tunn. Undergr. Space Technol. Inc. Trenchless Technol. Res. 2008, 23, 629-637. [CrossRef]

15. Lehmann, F. Practical application of non-destructive test methods at a single-shell tunnel lining. In Proceedings of the 7th International PhD Symposium in Civil Engineering, Stuttgart, Germany, 11-13 September 2008.

16. Song, K.I.; Cho, G.-C. Bonding state evaluation of tunnel shotcrete applied onto hard rocks using the impact-echo method. NDT E Int. 2009, 42, 487-500. [CrossRef]

17. Song, K.I.; Cho, G.-C. Numerical study on the evaluation of tunnel shotcrete using the Impact-Echo method coupled with Fourier transform and short-time Fourier transform. Int. J. Rock Mech. Min. Sci. 2010, 47, 1274-1288. [CrossRef]

18. Song, K.I.; Cho, G.C. Health Monitoring of Tunnel Shotcrete Lining Using Nondestructive Testing Methods. In Proceedings of the GeoFlorida, Orlando, FL, USA, 20-24 February 2010.

19. Boone, S.D.; Barr, P.J.; Bay, J.A. Nondestructive Analysis of a Concrete Tunnel Model Using a Newly Proposed Combined Stress Wave Propagation Method. J. Perform. Constr. Facil. 2009, 23, 432-439. [CrossRef]

20. Gibon, A. Advances in Shotcrete Impact-Echo Testing; CRC Press: London, UK, 2010.

21. Ryden, N.; Aurell, O.; Nilsson, P.; Hartlén, J. Impact Echo Q-Factor Measurements Towards Non-Destructive Quality Control of the Backfill in Segmental Lined Tunnels; Springer: City, The Netherlands, 2013.

22. Azari, H.; Soheil Nazarian, P.E.; Yuan, D. Case Study on Tunnel Lining Assessment Using Stress Wave-Based Nondestructive Testing Methods. In Proceedings of the Geo-Congress, Atlanta, GA, USA, 23-26 February 2014.

23. Cao, R.N.; Ma, M.; Liang, R.H.; Niu, C. Detecting the Void behind the Tunnel Lining by Impact-Echo Methods with Different Signal Analysis Approaches. Appl Sci. 2019, 9, 3280. [CrossRef]

24. Huang, W.D.; Y., H.T.; Li, Z.X. Study of the boundary effect on the stiff model box. In Proceedings of the Construction and Management of Subaqueous Tunnel, Nanjing, Jiangsu, China, 28 November 2013.

25. Code, C.N. Standard for Engineering Classification of Soil; China Planning Press: Beijing, China, 2008; GB/T 50145-2007.

26. Shiotani, T.; Bisschop, J.; Mier, J.G.M.V. Temporal and spatial development of drying shrinkage cracking in cement-based materials. Eng. Fract. Mech. 2003, 70, 1509-1525. [CrossRef]

27. Mandelbrot, B.B. The Fractal Geometry of Nature. Am. J. Phys. 1983, 51, 286. [CrossRef]

28. Maragos, P.; Sun, F.-K. Measuring the Fractal Dimension of Signals: Morphological Covers and Iterative Optimization. IEEE Trans. Signal Process. 1993, 41, 108. [CrossRef]

29. Lou, J.W.; Long, Y.; Xu, Q.J.; WAN, W.Q. A study on the fractal dimension of blasting seismic waves. Explos. Shock Waves 2004, 24, 363-369. [CrossRef] 
30. Timoshenko, S. Vibration Problems in Engineering, 2nd ed.; Wolfenden Press: New York, NY, USA, 1937.

31. Solodov, I.; Bai, J.; Busse, G. Resonant ultrasound spectroscopy of defects: Case study of flat-bottomed holes. J. Appl. Phys. 2013, 113, 26-31. [CrossRef] 